\title{
Evaluating the potential of carbonate sub-facies classification using NMR longitudinal over transverse relaxation time ratio
}

\author{
Fan Zhang ${ }^{1}$, Chi Zhang ${ }^{1,2}{ }^{1 *}$ \\ ${ }^{1}$ Department of Geology, University of Kansas, Lawrence, KS, United States \\ ${ }^{2}$ Currently in the Institute for Meteorology and Geophysics, University of Vienna, Vienna, Austria
}

Keywords:

NMR logging

$T_{1} / T_{2}$ ratio

lithology indicator

carbonate lithofacies

Cited as:

Zhang, F., Zhang, C. Evaluating the potential of carbonate sub-facies classification using NMR longitudinal over transverse relaxation time ratio. Advances in Geo-Energy Research, 2021, 5(1): 87-103, doi:

10.46690/ager.2021.01.09

\begin{abstract}
:
While the well log-based lithology classification has been extensively utilized in reservoir characterization, the classification of carbonate sub-facies remains challenging due to the subtle nuances in conventional well-logs. The nuclear magnetic resonance (NMR) log provides extra information of pore size and pore geometry features, improving differentiating carbonate sub-facies. Here we explore the feasibility of using the ratio between NMR longitudinal relaxation time and transverse relaxation time as a potential lithology indicator to determine carbonate sub-facies. We analyzed a series of logging data and corresponding core samples of Arbuckle Group carbonate containing mudstone, packstone, grainstone, incipient breccia, and breccia in northern Kansas for the characteristics of longitudinal relaxation times, transverse relaxation times, and longitudinal over transverse relaxation time ratios. The results show that mudstone, packstone, and grainstone exhibit high, intermediate, and low longitudinal over transverse relaxation time ratios, respectively, while incipient breccia and breccia have a wide range of longitudinal over transverse relaxation time ratios. Furthermore, we evaluated the potential of using longitudinal over transverse relaxation time ratios to classify carbonate sub-facies using multivariate analysis. By adding longitudinal over transverse relaxation time ratios to neutron porosity, total gamma-ray, and conductivity logs as inputs of automated facies classification, the prediction error decreased, especially for incipient breccia. On the contrary, when photoelectric log and computed gamma-ray are also available, adding longitudinal over transverse relaxation time ratios does not improve the accuracy of sub-facies classification. Our results suggest that longitudinal over transverse relaxation time ratio is an independent lithology indicator. However, it cannot replace other logs like gamma-ray and photoelectric logs in classifying carbonate sub-facies. Our study provided valuable evidence and credible elucidation of the importance and physicochemical mechanism of longitudinal over transverse relaxation time ratios, which is essential for deciphering NMR logging data in carbonate reservoirs.
\end{abstract}

\section{Introduction}

The primary task of petrophysical studies is to provide a full picture of the tightly coupled physical and chemical processes that govern the behavior of reservoir rocks and their constituent fluids. Petrophysical properties such as porosity, saturation, and permeability can be derived from well log responses, and represent the critical inputs of rock typing and subsurface geologic models (Busch et al., 1987; Delfiner et al., 1987). The classification of lithology from well logs is crucial to reservoir evaluation as the logs reflect the mineralogical and physical properties of the subsurface. Early attempts in the early 1980s to predict lithologies from log responses to augment core description used empirical geological facies-log response associations. Serra and Abbott (1982) developed the concept of electrofacies, defined as collective wireline logging responses that uniquely distinguish facies from one another, as a measure to extend the petrophysical properties identified in the core to the borehole scale. Numerous logs, including environment logs (e.g., temperature, pressure, and caliper logs), lithology logs (e.g., gamma-ray and density $\operatorname{logs}$ ), neutron log, and resistivity log provide distinct information on the reservoir, can be grouped or clustered to define electrofacies, which are essential for reservoir characterization (Bucheb and Evans,

\section{Yandy
Scientific}

Press
${ }^{*}$ Corresponding author.

E-mail address: f001z459@ku.edu (F. Zhang); chi.zhang@univie.ac.at (C. Zhang).

2207-9963 () The Author(s) 2021.

Received February 22, 2021; revised March 5, 2021; accepted March 5, 2021; available online March 8, 2021. 
1994; Mathisen et al., 2001; Kim et al., 2005; Perez et al., 2005; Lim et al., 2006; Ali et al., 2008; Sharma et al., 2011).

Among these borehole well logs, nuclear magnetic resonance (NMR) wireline tools such as magnetic resonance imaging logging (MRIL) has created excitement in the well logging community. NMR is a geophysical method providing fluid content and porous structure of porous media due to its direct sensitivity to hydrogen (Coates, et al., 1999). In the past few decades, the NMR technique has been successfully applied in well logging and laboratory to estimate water content, porosity, pore size distribution, irreducible and free water content, and permeability (for detailed reviews, see Coates et al. (1999) and Dunn et al. (2002)). Combining with other logs, NMR log has been applied to zonation and lithology classification (or rock typing) for the last two decades. Previous studies use NMR $\log$ to identify the lithology by analyzing the partitioning of the pore size distribution (Doveton and Watney, 2015) and the variation of $\log$ mean relaxation time $\left(T_{2 m l}\right)$ (Skalinski et al., 2006; Rastegarnia et al., 2017). However, there are other information from NMR logs are not fully exploited in rock typing, such as the longitudinal $\left(T_{1}\right)$ to transverse $\left(T_{2}\right)$ relaxation time ratio- $T_{1} / T_{2}$. The $T_{1} / T_{2}$ ratio has been interpreted as an indicator of the molecular environment of hydrogen proton (Callaghan, 1991; McDonald et al., 2005). In bulk and unrestricted space, without the diffusion of the fluid, the $T_{1} / T_{2}$ value is equal to one (Kleinberg et al., 1993b). Within a confined environment, such as a pore, decreasing $T_{2}$ corresponds to the restricted motion of water molecules, whereas increasing $T_{1}$ indicates more ordered lattice structure and higher crystallinity (Callaghan, 1991). These results suggest that $T_{1} / T_{2}$ value would be higher in more ordered materials, and in materials with smaller pores.

Kleinberg et al. (1994) suggested an average $T_{1} / T_{2}=1.6$ for 6 sandstone samples and the higher clay content and metal content will increase the $T_{1} / T_{2}$ ratio due to the higher content of the paramagnetic particle. Korb et al. (1997) and Godefroy et al. (2001) gave an explicit expression of the frequency dependent $T_{1} / T_{2}$ ratio. Given the fact that the NMR frequency of electron is way larger than the NMR frequency of proton, the expression of $T_{1} / T_{2}$ ratio can be simplified as

$$
\frac{T_{1}}{T_{2}}=\frac{16 \ln \frac{\tau_{m}}{\tau_{s}}+3 \ln \frac{1+\left(\omega_{p} \tau_{m}\right)^{2}}{\frac{\tau_{m}}{\tau_{s}}+\left(\omega_{p} \tau_{m}\right)^{2}}}{6 \ln \frac{1+\left(\omega_{p} \tau_{m}\right)^{2}}{\frac{\tau_{m}}{\tau_{s}}+\left(\omega_{p} \tau_{m}\right)^{2}}}
$$

where $\tau_{m}$ is the surface diffusion correlation time describes the molecular jumps of adsorbed molecules, for instance, water molecules which diffuse across the pore surface, and $\tau_{s}$ is the surface residence time describes the time period of water molecules staying on the pore surface, and $\omega_{p}$ is the NMR frequency of proton $\left({ }^{1} \mathrm{H}\right.$ in water molecules). The $\tau_{m} / \tau_{s}$ has a range from $10^{-2}$ to $10^{-4}$ and $\omega_{p} \tau_{m} \gg \tau_{m} / \tau_{s}$ (McDonald et al., $2005)$. Both modeling and experiments support that $T_{1} / T_{2}$ ratio has the potential to be an indicator for lithology. For instance, rocks with various minerals and compositions should have distinct surface environments yielding various $T_{1} / T_{2}$ ratios.

The purpose of our study is to evaluate the potential of using $T_{1} / T_{2}$ ratio derived from NMR logs to determine carbonate sub-facies. We analyzed the well logs and core samples from Arbuckle Group in Wellington (\#1-32) in Sumner County, Kansas. A dolomite interval contains five sub-facies (mudstone, packstone, grainstone, incipient breccia, breccia) is selected and tested. The core samples were also measured by lab NMR to validate the sensitivity of $T_{1} / T_{2}$ ratio to lithology. The $T_{1} / T_{2}$ ratio is integrated with other logs to perform an electrofacies classification using principal component analysis and fuzzy-C mean clustering to predict carbonate sub-facies. The prediction accuracies are compared among four different $\log$ sets to assess the contribution of $T_{1} / T_{2}$ ratio as lithology indicators. Our results confirmed that $T_{1} / T_{2}$ ratio is an independent lithology indicator, but it cannot replace other logs like gamma-ray and photoelectric log in determining carbonate sub-facies. Our study is the first attempt to exploit the full potential of NMR logging data in characterizing petrophysical properties of carbonate reservoir rocks by investigating $T_{1} / T_{2}$ ratio through linking NMR theoretical background with core experimental data and NMR log data. Our study provided valuable evidence and credible elucidation of the importance and physicochemical mechanism of $T_{1} / T_{2}$, which is essential for deciphering NMR logging data in carbonate reservoirs.

\section{New theory}

\subsection{NMR fundamentals}

The fundamental physical principle of NMR is the behavior of the nuclei. In the presence of a background magnetic field $\left(B_{0}\right)$, the nuclear spins associated with the hydrogen nuclei are oriented in the direction parallel to the background field, which can be tipped out of alignment by an external radiofrequency (RF) magnetic field $\left(B_{1}\right)$. After the removal of the external field, the nucleus relaxes back to equilibrium. Regular NMR measurement generates two main relaxation results: $T_{1}$ and $T_{2}$ relaxation time. The magnitude of the relaxation decay is proportional to water content, while the distribution of relaxation time $\left(T_{1}\right.$ or $\left.T_{2}\right)$ can be used to estimate pore size distribution, irreducible and movable liquid saturation, surface area-to-volume ratios, and hydraulic conductivity (Coates et al., 1999). The relaxation time distribution is linked to three different mechanisms (Kleinberg et al., 1994; Westphal et al., 2005).

$$
\begin{gathered}
\frac{1}{T_{1}}=\frac{1}{T_{1 B}}+\frac{1}{T_{1 S}} \\
\frac{1}{T_{2}}=\frac{1}{T_{2 B}}+\frac{1}{T_{2 S}}+\frac{1}{T_{2 D}}
\end{gathered}
$$

where the subscripts $B, S, D$ represent bulk fluid (free fluid) relaxation, surface relaxation, and molecular diffusion, respectively. Bulk fluid relaxation times $\left(T_{1 B}\right.$ and $\left.T_{2 B}\right)$ are the relaxation time of free fluid $\left(3.82 \mathrm{~s}\right.$ at $30{ }^{\circ} \mathrm{C}$ (Simpson and Carr, 1958)). In geologic media, we assume a fast diffusion regime, the bulk fluid contribution $\left(1 / T_{1 B}\right.$ and $\left.1 / T_{2 B}\right)$ and the 
diffusion relaxation $\left(1 / T_{2 D}\right)$ can be neglected. Thus,

$$
\frac{1}{T_{1,2}} \approx \frac{1}{T_{1,2 S}}+\rho_{1,2} \frac{S}{V}
$$

where $\rho_{1,2}$ is the surface relaxivity corresponding to the capability of relaxation enhancement on the surface, $S$ and $V$ are the surface area and volume of pore space, respectively. Hence, $T_{1,2}$ is proportional to the surface area to volume ratio $S / V$ (will be presented as $S_{\text {por }}$ below) and pore size. Accurate determination of surface relaxivity $\rho_{1,2}$ is crucial in estimating pore size distribution and is usually resolved by calibrating NMR relaxation time using mercury intrusion capillary pressure or/and gas adsorption experiments.

\subsection{Calculation of $T_{1} / T_{2}$ ratio}

From the basic principles of NMR, $T_{1}$ and $T_{2}$ spectra are very similar in shape. Therefore, the $T_{1} / T_{2}$ ratio can be simply considered as a scaler of longitudinal relaxation time distribution versus transverse relaxation time distribution. The intensity function $a_{1,2}$ of both longitudinal and transverse relaxation time (Khetrapal et al., 1975; Kleinberg et al., 1994) can be derived from the following equations:

$$
\begin{gathered}
M_{1}(t)=\sum_{i=0} a_{1}\left(T_{1 i}\right)\left(1-2 e^{-\frac{t}{T_{1 i}}}\right) \\
M_{2}(t)=\sum_{i=0} a_{2}\left(T_{2 i}\right) e^{-\frac{t}{T_{2 i}}}
\end{gathered}
$$

where $t$ is the time for one pulse train, $M_{1}$ and $M_{2}$ are the magnitude of magnetizations. To calculate $T_{1} / T_{2}$ ratio, both $a_{1}$ and $a_{2}$ are required (Kleinberg et al., 1993a). For instance, $a_{1}$ and $a_{2}$ are intensity functions for discrete relaxation times $T_{i}$ $(i=4,8, \ldots, 2048 \mathrm{~ms})$. The zero-normalized cross-correlation coefficient, $P$, can be calculated as

$$
P_{a_{1} a_{2}}(\omega)=\sum_{i=0} \frac{\left[a_{1}\left(T_{1 i}\right)-a_{1}\left(\overline{T_{1}}\right)\right]\left[a_{2}\left(\omega T_{2 i}\right)-a_{2}\left(\omega \overline{T_{2}}\right)\right]}{\sigma_{a_{1}} \sigma_{a_{2}}}
$$

where $\omega$ is the $T_{1} / T_{2}$ ratio, $\sigma_{a_{1}}$ and $\sigma_{a_{2}}$ are the standard deviation of amplitudes of $T_{1}$ and $T_{2}$ spectrums, $\overline{T_{1}}$ and $\overline{T_{2}}$ are the mean value of $T_{1}$ and $T_{2}$. This simplified correlation function is constrained by the shape and range of $T_{1}$ and $T_{2}$ distributions. Although $\omega$ can be obtained by maximizing $P_{a_{1} a_{2}}(\omega)$, the effective range of $i$ should be carefully selected with fully considering the saturation, saturation fluids, and the development of microfractures (Kleinberg et al., 1993b; Song et al., 2002).

\section{Litholofacies prediction}

\subsection{Petrophysical recognition of mineralogy}

Single variable methods generally are used for early-stage and current electrofacies recognition. For example, Flaum and Pirie (1981) applied spectral gamma-ray to quantitatively subdivide sandstone, clay, limestone in strata of the Cotton Valley Group (Jurassic) in eastern Texas, and Lucia (2007) successfully subdivided mud-supported carbonate and grainsupported carbonate in San Andres and Grayburg formations
(Permian) in western Texas using computed gamma-ray log. However, the single variable analysis is not applicable to clean reservoir rocks with no clay, e.g., sandstone, or highly heterogeneous lithologies, e.g., carbonate.

In most strata, integrating more logs is necessary for electrofacies recognition. Litho-porosity cross-plots like the M-N plot (Burke et al., 1969), which combines neutron $\log$, density $\log$, and sonic $\log$, is another frequently used electrofacies discriminator. However, in this approach, ' $M$ ' and ' $\mathrm{N}$ ' are created without correlations with physical properties. To improve the litho-porosity method, Clavier and Rust (1976) developed the matrix-identification (MID) plot, which is also called $U_{\text {maa }}$ vs. $\rho_{\text {maa }}$ plot. It uses two quasi-physical quantities: apparent matrix density $\left(\rho_{\text {maa }}\right)$ in $\mathrm{g} / \mathrm{cc}$ and apparent volumetric cross section of photoelectric absorption $\left(U_{\text {maa }}\right)$ in barns/cc calculated by:

$$
\begin{gathered}
\rho_{\text {maa }}=\frac{\rho_{b}-\rho_{f} \varphi_{t}}{1-\varphi_{t}} \\
U_{\text {maa }}=\frac{P_{e} F \rho_{b}-U_{f} \varphi_{t}}{1-\varphi_{t}}
\end{gathered}
$$

where $\rho_{b}$ is bulk density, $\rho_{f}$ is the fluid density, $\varphi_{t}$ is true volumetric porosity, $P_{e}$ is photoelectric absorption measurement, $P_{e} F$ is the photoelectric absorption factor, and $U_{f}$ is the fluid volumetric photoelectric absorption. More recently, third-generation density $\operatorname{logs}$ (litho-density $\log$ ) provide an additional photoelectric measurement. $P_{e}$, which reflects the average atomic number of the formation, is a reliable indicator of the formation lithology (Dewan, 1983). In carbonate reservoir logging analysis, three end-member minerals (quartz, calcite, dolomite) can be plotted in a triangle on the $U_{\text {maa }}$ and $\rho_{\text {maa }}$ cross plot based on standard $U_{\text {maa }}$ and $\rho_{\text {maa }}$ values from various minerals. End-member $\rho_{\text {maa }}$ values for pure quartz, calcite, and dolomite are 2.65, 2.71 and $2.87 \mathrm{~g} / \mathrm{cc}$, respectively, whereas the end-member values $U_{\text {maa }}$ for quartz, calcite, and dolomite are 4.78, 13.80 and 8.98 barns/cc, respectively (Poupon et al., 1971). The artificial or formalized parameters are defined to be independent of porosity (Doveton, 2014). If the pore characteristics dominate the log signals, the MID and $U_{\text {maa }}-\rho_{\text {maa }}$ triangle approaches are less accurate.

\subsection{Automated electrofacies classification}

To obtain more representative electrofacies from well logs, an alternative method is proposed to use multivariate data analysis to correlate well logs with core descriptions. The multivariate data analysis is expected to improve petrophysical properties estimation by clustering the logs with similar characteristics into groups (electrofacies). With the blooming of computational power, the use of mathematical procedures and computer programs to automatically classify electrofacies from even more complex set of variables has become more common (Doveton and Cable, 1979; Busch et al., 1987; Delfiner et al., 1987; Grimm, 1987; Bucheb and Evans, 1994). One complete multivariate statistical analysis includes analysis of variance, nonparametric regression, clustering, and classification. In our study, the analysis follows three steps: 1) Principal component 
analysis (PCA); 2) Fuzzy c-mean clustering; and 3) Classification. The logs were first transformed into PCA scores, which are then subjected to model-based clustering, and lastly, to be categorized into groups that can be interpreted as electrofacies. The details of each step are discussed below.

\subsubsection{Step 1: PCA}

PCA is a multivariate technique in which several related variables are transformed into a set of uncorrelated variables (Jolliffe, 2011). The most significant advantage of PCA is the simplification of data by reducing its dimensionality, and it facilitates extraction of the structure of variables. This procedure is vital in the modern well logging analysis as logging suites provide closely correlated logs, challenging the multivariate analysis.

In PCA, all logs first should be normalized with zero-score standardization, which subtracts the mean and standardizes data to the unit deviation of each $\log$ to ensure the equal weight of each response. The first two principal components (PC1, PC2) are selected to address the score plot. Since most of the dataset variability is contained in the first two PCs, noise collected in the observations can be extracted and eliminated from the original data suite. However, even if well logs can be projected into uncorrelated variables, it is unrealistic to establish connections between principal components and actual petrophysical properties, different from the capabilities of core descriptions and logs.

\subsubsection{Step 2: Clustering}

Cluster analysis is used as a primary stage for unsupervised learning to group the dataset into subsets so that similar instances are grouped, whereas different instances belong to different groups (Rokach and Maimon, 2005). The purpose of the cluster analysis is to separate the data from a suite of logs into meaningful groups that can be interpreted in terms of electrofacies. Standard clustering algorithms use a hard boundary, only allowing a component to be in one cluster. The dataset can be divided into several subgroups using centroidbased algorithms (K-mean clustering, mean-shift clustering), density-based algorithms, hierarchical development, or neural network algorithms (see Jain (2010) for a review of details of current pattern recognition and clustering methods). However, since the underlying algorithms are intended to be efficient for pattern recognition instead of revealing physical mechanisms, these methods do not perform well if the clusters are not drastically separated. Sub-facies with very similar petrophysical properties like packstones and mudstones usually overlap in the score maps and are challenging to be isolated. Therefore, hard boundaries are not preferred for electrofacies classification. Fuzzy c-means (FCM) is a method of centroid-based clustering (Dunn, 1973; Bezdek et al., 1984) which employs fuzzy membership and allows one data point to belong to many (or even all) clusters with degrees of membership from 0 to 1 (e.g., the total membership =1) (one can refer to Appendix A for the detailed theory of FCM algorithm). Unlike hard boundary clustering, FCM allows a changeable clustering result by adjusting the membership threshold to each cluster, giving the best result for the overlapped dataset. Usually, the
FCM is better than the k-means algorithm in recognizing members with characteristics of multiple groups (Bezdek, 1981). For instance, mudstone, packstone, and grainstone can have very similar PC1 and PC2 values, closing cluster centers. Therefore, FCM would be less successful in recognizing subfacies that include a mudstone surrounded by the packstone and grainstone in the score plot.

\subsubsection{Step 3: Classification}

The last step is to assign lithologies to clusters to provide them meaningful electrofacies. This procedure is usually performed by either applying the lithologies of centroid to the whole cluster universally (Doveton, 2014) or assigning lithologies based on their corresponding logs and log interpretations (Roslin and Esterle, 2016). However, those two methods rely on 1) a relatively large number of clusters; and 2) distinct log values among clusters and thorough understanding of these log values. These two conditions are not satisfied in this study as our carbonate samples are with a fixed number of clusters and have relatively small changes in log responses. To avoid human bias while assigning the lithologies to clusters and make this interpretive procedure into an unsupervised way, we applied a statistical method to minimize the overall objective function $S$ :

$$
S=\phi_{m}+\beta \phi_{n}
$$

where $\phi_{m}$ is data misfit and $\phi_{m}=\sum_{i=1}^{n}\left[\left(d_{i}^{e}-d_{i}^{l}\right) / \sigma\right]^{2}, d_{i}^{e}$ and $d_{i}^{l}$ are the electrofacies and lithologies for ith data point respectively, $\sigma$ is the standard deviation of the dataset, and $n$ is the total number of data points. $\phi_{n}$ is representing the model norm or regularizer and

$$
\phi_{n}=\alpha \sum_{i=1}^{n-1}\left(d_{i+1}^{\text {elec }}-d_{i}^{\text {elec }}\right)^{2}+(1-\alpha) \| \text { misprediction rate } \|_{2}^{2}
$$

Electrofacies that do not match lithologies would be considered as mispredicted. The misprediction rate is simply the number of mispredicted data points over the total number of data points. Therefore, $\phi_{n}$ contains the information of the smoothness of rock type transactions and the success rate of prediction. Weighting parameter $\alpha$ and $\beta$ are used to adjust the weight among terms and can be optimized, $\alpha$ is the weight between the smoothness of rock type transactions and the success rate of prediction and $\beta$ is the weight between data misfit and model norm.

\section{Material and method}

\subsection{Geological setting, well logs, and cores}

Well logs and core plug samples used in this study were from the deep subsurface (4900 to $5000 \mathrm{ft}$ ) from the well Wellington \#1-32 in Sumner County, Kansas (Fig. 1). Wellington \#1-32 was logged with photoelectric (PE), neutron porosity (NPHI), 90 inch conductivity (CT90), gamma-ray total (GRTO), potassium (POTA. \%), uranium (URAN. ppm), thorium (THOR. ppm), and MRIL. Our target interval of the well Wellington \#1-32 is the lower Cambro-Ordovician Arbuckle 


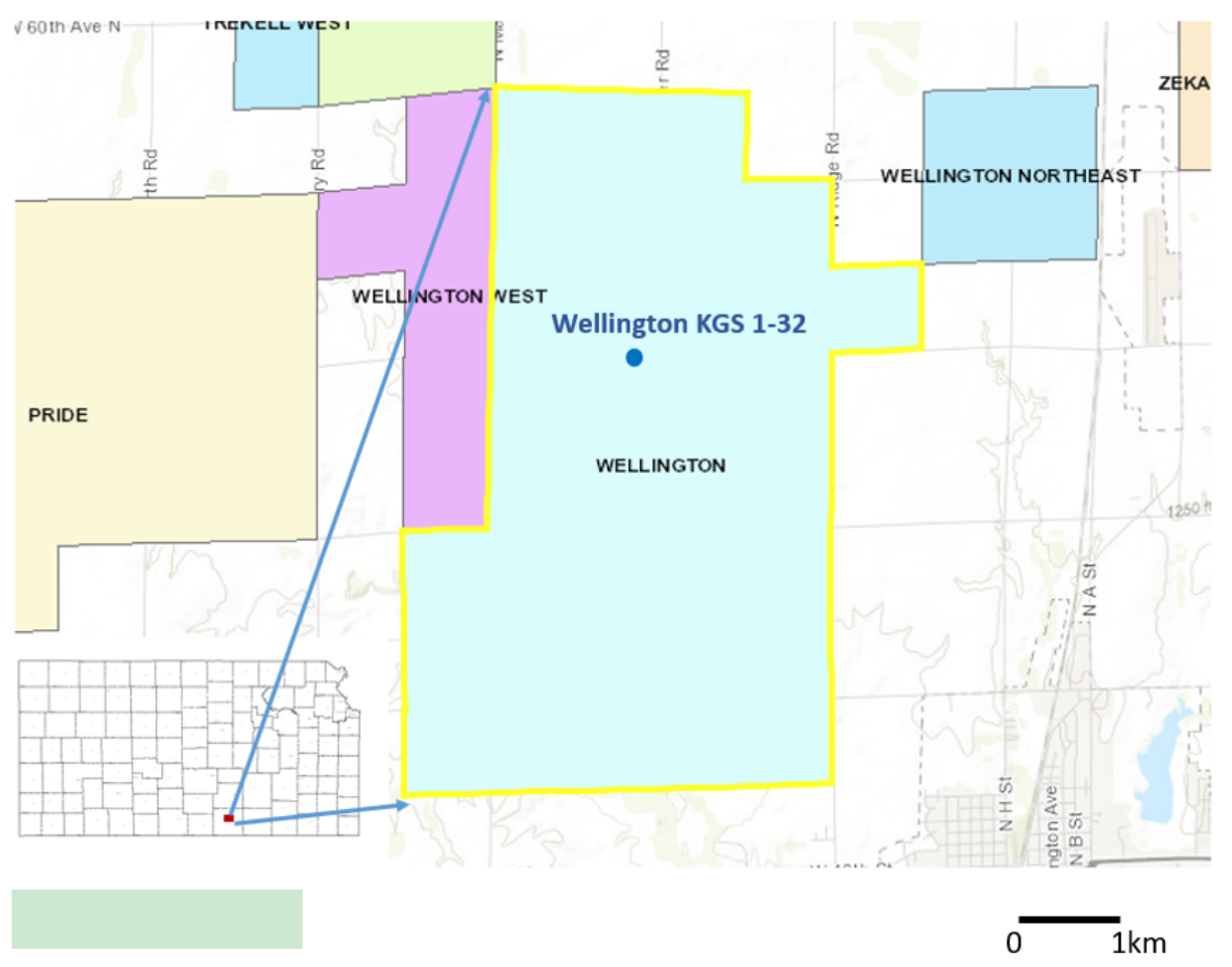

Fig. 1. The location of well Wellington KGS \#1-32 is presented on a Kansas map. The light blue area with yellow outlines is the Wellington oil and gas field. The blue dot marks the location of Wellington KGS \#1-32.

Table 1. Porosity, volumes, permeabilities, $T_{1} / T_{2}$ ratios from core and logs for each sub-facies.

\begin{tabular}{lllllll}
\hline Sub-facies (Based on core) & Porosity & Volume $(\mathrm{ml})$ & Permeability $(\mathrm{mD})$ & $T_{1} / T_{2}$ core & $T_{1} / T_{2} \log *$ & $T_{1} / T_{2} \log$ average $\dagger$ \\
\hline MS & 2.3 & 38.5 & 2.95 & 3.9 & 3.220 & 2.556 \\
PS & 8.5 & 22.3 & 0.06 & 2.6 & 2.300 & 2.502 \\
GS & 9.72 & 38.3 & 202.61 & 1.6 & 1.346 & 2.339 \\
IB & 3.36 & 21.1 & 88.9 & $1.3,2.3,3.4$ & 1.274 & 1.834 \\
BC & 9.77 & 41.9 & 3.7 & 2.5 & 2.793 & 2.820 \\
\hline
\end{tabular}

Note: Sub-facies are discriminated based on core observations where MS=mudstone, $\mathrm{PS}=$ packstone, GS=grainstone, IB=incipient breccia, and $\mathrm{BC}=$ breccia.

*log data are from the same depths as core plug samples.

$\dagger$ averaged over the entire depth.

Group. The Arbuckle Group is recognized as strata dominated by cherty dolostone, dolostone, and bedded limestone (Barwick, 1928; Zeller, 1968; Cole, 1975) and was developed in the southern Great American Carbonate Bank. The lithologies of the Arbuckle Group reflect a cyclical depositional environment from shallow subtidal to intertidal conditions (Franseen, 1994). The sub-facies of Arbuckle Group in well Wellington \#132 include mudstone, packstone, grainstone, incipient breccia, and breccia. Grainstone consists of intraclasts, ooids, peloids, and skeletal fragments. It represents high-energy deposition in subtidal to peritidal environments. The well-cemented pores lead to the low permeability of the samples. Packstone and mudstone are mainly massive to horizontally laminated with porosities from $3 \%$ to around $20 \%$. Breccias are commonly associated with subaerial exposure. Seawater evaporation leads to evaporite deposition, and the dissolution of evaporite, in turn, induced collapse horizons in Arbuckle strata. In short, due to its heterogeneous texture, breccia exhibits a wide range of porosity and permeability. Franseen $(1994,2000)$ and Steinhauff et al. (1998) identified lithological characteristics of the Arbuckle Group in Kansas. They concluded that although Arbuckle carbonates have been extensively dolomitized, their original depositional facies and textures are much preserved as the dolomitization is non-fabric destructive. We carefully selected five core plug samples, one from each carbonate subfacies. Table 1 shows the lithologies, porosities volumes, and air permeabilities with Klinkenberg correction $\left(K_{\text {air }}\right)$ of core plug samples. 

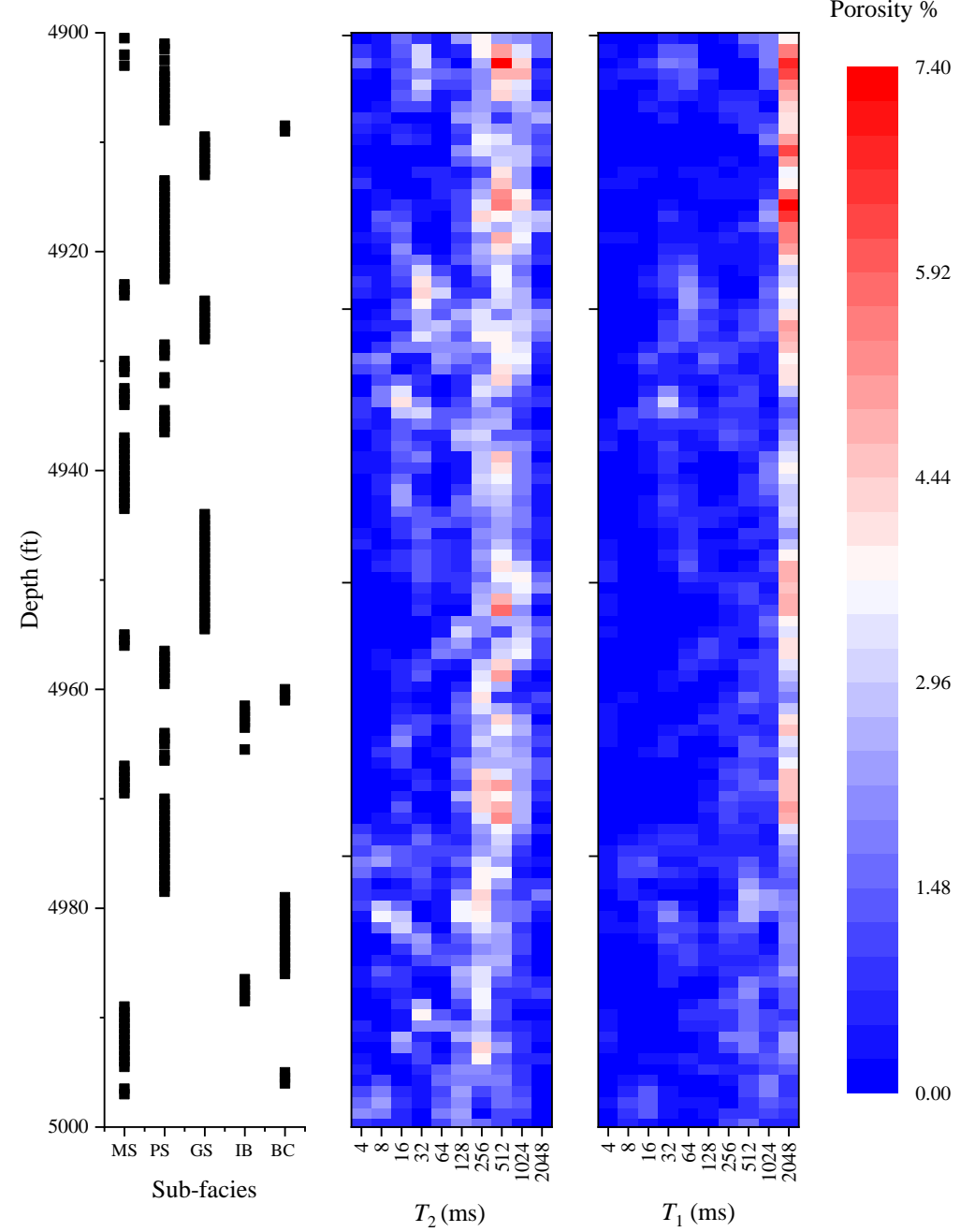

Fig. 2. Sub-facies of samples (where $\mathrm{MS}=$ mudstone, $\mathrm{PS}=$ packstone, $\mathrm{GS}=$ grainstone, $\mathrm{IB}=$ incipient breccia, $\mathrm{BC}=$ breccia) from the interval of interest (4900-5000 ft) are listed in the order of depth along with the corresponding $T_{2}$ and $T_{1}$ distributions. Note that NMR relaxation data are subdivided into bins with $2^{n}(\mathrm{n} \in[2,10]) \mathrm{ms}$ (as provided by the service company). Also, note some samples are missing from the lithofacies (4901, 4920-4923, and 4997-5000 $\mathrm{ft}$ ), which will be removed from the subsequent analyses.

\subsection{Laboratory NMR measurements}

Five samples are selected for lab experiments to present each lithology. Mudstone, packstone, grainstone, and incipient breccia samples are from the target interval. The breccia sample tested in our experiment is picked out of our target interval from the depth of $3172 \mathrm{ft}$, as no breccia sample is recovered in the target interval. All core samples were first oven-dried at $70{ }^{\circ} \mathrm{C}$ for 48 hours and placed under a vacuum with deionized water for 48 hours to adequately saturate the effective pore space. All samples were wrapped with Teflon tape after saturation to prevent water run-off. Laboratory NMR experiments were taken at $27{ }^{\circ} \mathrm{C}$ using a $2 \mathrm{MHz}$ Rock Core Analyzer (Magritek Ltd). The core samples were tested in the lab using a $2 \mathrm{MHz}$ Rock Core Analyzer (Magritek Ltd) for 1) $T_{1}$ measurements using Inversion Recovery (IR) pulse sequence (Kenyon et al., 1988) with 20 recovery time $\tau_{1}$ from 0.1 to $5000 \mathrm{~ms}$; 2) $T_{2}$ measurements using Carr-PurcellMeiboom-Grill (CPMG) pulse sequence (Carr and Purcell, 1954; Meiboom and Gill, 1958) with echo times of $200 \mu \mathrm{s}$, and inter-experiment time of $15000 \mathrm{~ms}$; and 3) $T_{1}-T_{2} 2 \mathrm{D}$ correlation measurements using an IR-CPMG pulse sequence (Song et al., 2002). A minimum of 32 scans were stacked together to improve the signal-to-noise ratio (SNR) for all three measurements. The recorded $T_{1}$ and $T_{2}$ were inverted using the Laplace inversion algorithm, and $T_{1}-T_{2}$ correlations were inverted using a fast iterative shrinkage-thresholding algorithm (FISTA).

\section{Reslts and discussion}

\section{1 $T_{1}$ and $T_{2}$ distributions}

Fig. 2 shows lithologies and corresponding $T_{2}$ and $T_{1}$ distributions within our target depth interval of 4900 to 5000 $\mathrm{ft}$. Overall, the transverse relaxation rate $1 / T_{2}$ is larger than the longitudinal relaxation rate $1 / T_{1}$. It is noteworthy that most of the porosities in $T_{1}$ distributions are accumulated in the bin $T_{1}$ $=2048 \mathrm{~ms}$ which is due to the detecting cap of the equipment is set to $2048 \mathrm{~ms}$.

$T_{1}, T_{2}$, and $T_{1}-T_{2}$ measurements were performed for 

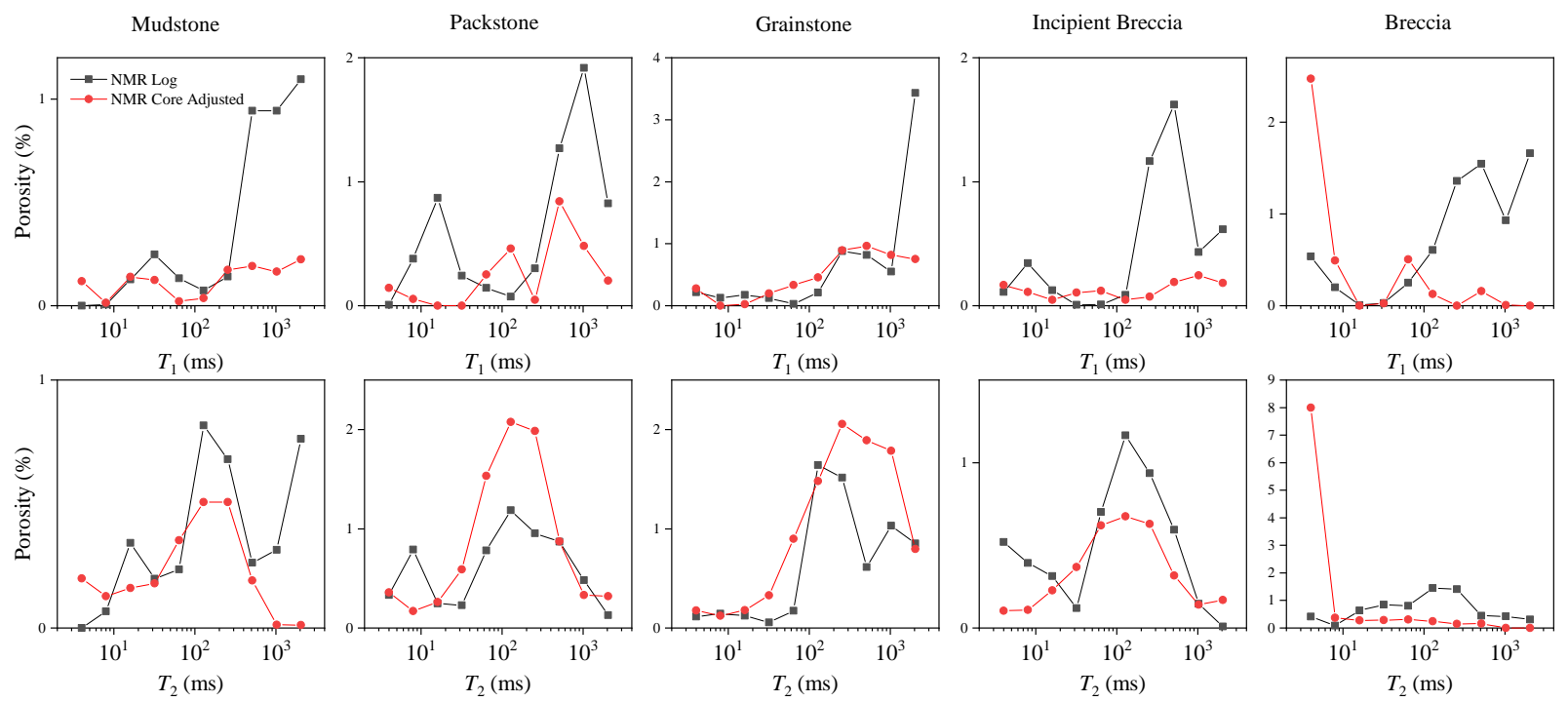

Fig. 3. The comparison of $T_{1}$ (upper row) and $T_{2}$ (lower row) spectra generated from NMR log and NMR core data for five sub-facies.

all five core-plug samples to obtain the characteristics of relaxation time distributions and $T_{1} / T_{2}$ ratios of each lithology. The $T_{1}$ and $T_{2}$ distributions from core measurements are compared with NMR logs in Fig. 3. In order to compare these two datasets on the same scale, incremental porosities from 200 relaxation steps $(0.1$ to $5000 \mathrm{~ms})$ are congregated to 8 data points ( 2 to $2048 \mathrm{~ms}$ ) for core measurement (NMR Core Adjusted in Fig. 3). Overall, $T_{2}$ distributions between NMR logs and NMR core measurements show better correlation than $T_{1}$ distributions. The shapes and positions of major peaks of $T_{2}$ distributions are very similar in NMR logs and core measurements. By contrast, $T_{1}$ distributions exhibit a general gap of porosity at higher relaxation time where NMR logs captured more porosities than NMR core measurements. While the NMR core measurement captures a higher porosity than the log results below $2 \mathrm{~ms}$ in the breccia sample.

The major discrepancy at high relaxation time could be explained by two possible reasons. Firstly, the effective collecting area of NMR logging tools is $61 \mathrm{~cm}$ in diameter and $1.07 \mathrm{~m}$ in length, two to three times larger than the core plug sample size $\left(20-40 \mathrm{~cm}^{3}\right)$. Such a broader detecting range of NMR logging tools potentially increases the signals capture area that exceeds the core plug size. Additionally, the long measurement time of $T_{1}$ logging can capture signals from high relaxation time in multiple aperture volumes if the sonde moves fast (Kleinberg et al., 1993b; Coman et al., 2015). Due to these reasons, discrepancies of $T_{1}$ distributions between core experiments and NMR logs are more significant than that of $T_{2}$ distributions (Fig. 3). The discrepancy at low relaxation time, on the other hand, is caused by long echo time used in NMR log, which is $1.2 \mathrm{~ms}$ (Coates et al., 1999; Doveton and Watney, 2015). With a long echo time, signals from micropores which have relaxation times below $1.2 \mathrm{~ms}$ are not collected. Therefore, signals of samples with abundant micropores can be underestimated by NMR logging. The discrepancy of relaxation time distributions between core experiments and NMR logs can induce error while calculating the $T_{1} / T_{2}$. As shown in Eq. (7), we calculate $T_{1} / T_{2}$ by maximizing the zero-normalized cross-correlation $P_{a_{1} a_{2}}(\omega)$ where the intensity functions $a_{1}$ and $a_{2}$ are weighted by the standard deviation of $\sigma_{a_{1}}$ and $\sigma_{a_{2}}$. Therefore, as long as the major peak positions are the same in core experiments and logs (e.g., our mudstone, packstone, grainstone and breccia samples), the difference between intensity of the distribution spectra will not affect the $T_{1} / T_{2}$. However, samples that show unclear peaks (e.g., incipient breccia sample) might have very different core $T_{1} / T_{2}$ and $\log T_{1} / T_{2}$. Therefore, the weight of the intensity functions $a_{1}$ and $a_{2}$ have to be manually calibrated.

\section{$5.2 T_{1} / T_{2}$ ratio}

Due to the limitation mentioned above, the log derived $T_{1} / T_{2}$ ratios might deviate from the actual values. A comparison between $T_{1} / T_{2}$ derived from logging data and core experiments can elucidate the relationship between lithology and $T_{1} / T_{2}$. The lab $T_{1}-T_{2} 2 \mathrm{D}$ mapping results are presented in Fig. 4. The essential criteria for picking the $T_{1} / T_{2}$ value is to find the best fitting line should cross the peak amplitude for most pore families, which are defined as compartments of signals that are distinguishable from each other (Fleury and Romero-Sarmiento, 2016). According to these criteria, the best fitting $T_{1} / T_{2}$ for mudstone, packstone, grainstone, and breccia are 4.1, 2.6, 1.6, and 2.5, respectively. Incipient breccia, however, reveals at least three distinct pore families that associate with three different $T_{1} / T_{2}$ values as $1.3,2.3$, and 3.4. The change of $T_{1} / T_{2}$ is usually due to abundant free water that reduces the $T_{1} / T_{2}$ ratio at high relaxation time (d'Eurydice et al., 2016), and/or the existence of other fluid components (Fleury and Romero-Sarmiento, 2016). However, none of these attributions applies here since incipient breccia was only saturated by only water, and its $T_{1} / T_{2}$ ratio increases with the relaxation time. Therefore, we concluded the observed three pore families in incipient breccia $T_{1}-T_{2} 2 \mathrm{D}$ maps are associated with different mineral compositions of the autoclasts within incipient breccia. 

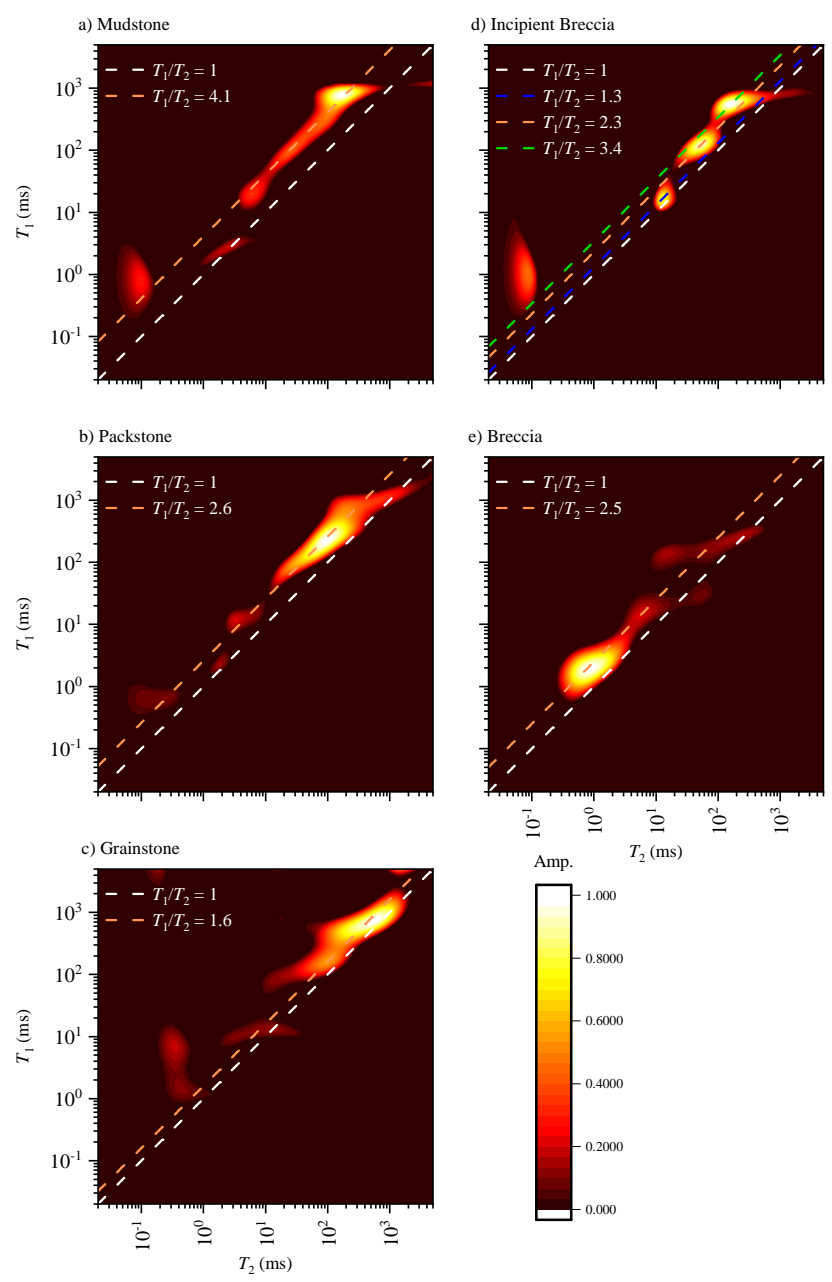

The logging $T_{1} / T_{2}$ values ranges from 0.66 to 7.44 , which are consistent with the measured $T_{1} / T_{2}$ values for carbonate samples (Kenyon et al., 1988; Cheng et al., 2017). Table 1 presents the $T_{1} / T_{2}$ for 5 core samples from both lab NMR and logging NMR, as well as the average $T_{1} / T_{2}$ values for five lithologies in the target interval. The $T_{1} / T_{2}$ decreases as the lithologies transit from mudstone to packstone, and then to grainstone. Breccia and incipient breccia have mixed $T_{1} / T_{2}$ values, but overall breccia has higher $T_{1} / T_{2}$. From these consistent evidence shown in both core and $\log$ data, $T_{1} / T_{2}$ has shown the potential to be an independent lithology indicator.

We use a ternary plot of quartz, calcite, and dolomite abundance to represent the mineral constituents of a carbonate reservoir (Fig. 5). The plot indicates that mineral components within the target interval are mostly quartz and dolomite, combined with a limited amount of calcite. High $\rho_{\text {maa }}$ and $U_{\text {maa }}$ indicates more dolomite content, while lower $\rho_{\text {maa }}$ and $U_{\text {maa }}$ reflects increasing silica (quartz) content. In Fig. 5(b), relatively high $T_{1} / T_{2}$ values $(>5)$ and relatively low $T_{1} / T_{2}$ values $(<2)$ correspond with highly dolomitic samples, whereas intermediate $T_{1} / T_{2}$ (2-5) samples are broadly distributed. The correlation between dolomite percentage and $T_{1} / T_{2}$ value suggests that $T_{1} / T_{2}$ can be affected by the mineral composition. The overlapping of low $T_{1} / T_{2}$ and high $T_{1} / T_{2}$ clusters highlights the fundamental shortcoming of MID plot, which limits the information only to 2D space.

\subsection{Electrofacies classification}

\subsubsection{PCA results}

Table 2 lists five lithologies and associated log responses, including $T_{1} / T_{2}$, apparent matrix density $\left(\rho_{\text {maa }}\right)$, matrix volumetric photoelectric absorption $\left(U_{\text {maa }}\right)$, total porosity (PHIT), lateral log CT90, total gamma-ray reading (GRTO), THOR, and POTA averaging over the target interval. Mudstone, packstone, and grainstone are high in NPHI, GTRO, $\rho_{\text {maa }}, U_{\text {maa }}$, $T_{1} / T_{2}$ and low in CT90 comparing with incipient breccia and is for $T_{1} / T_{2}=3.4$.

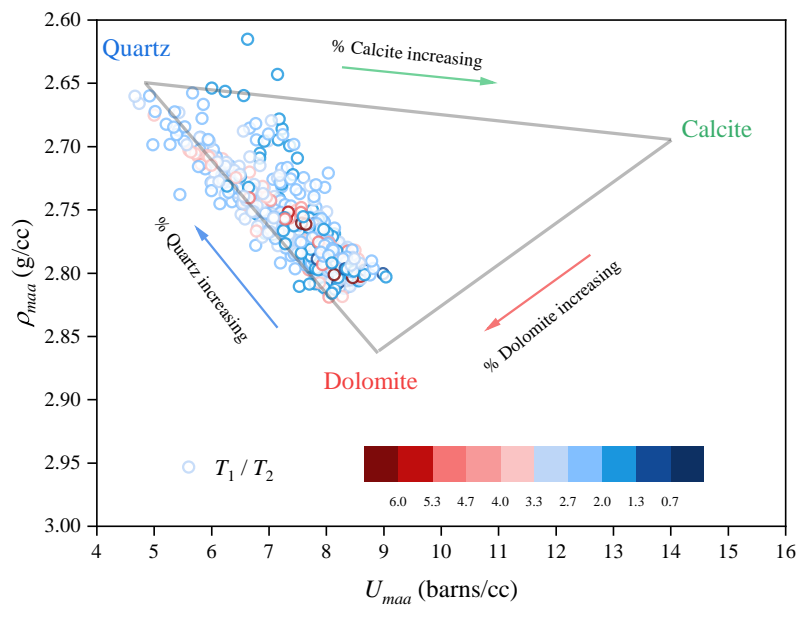

(a)

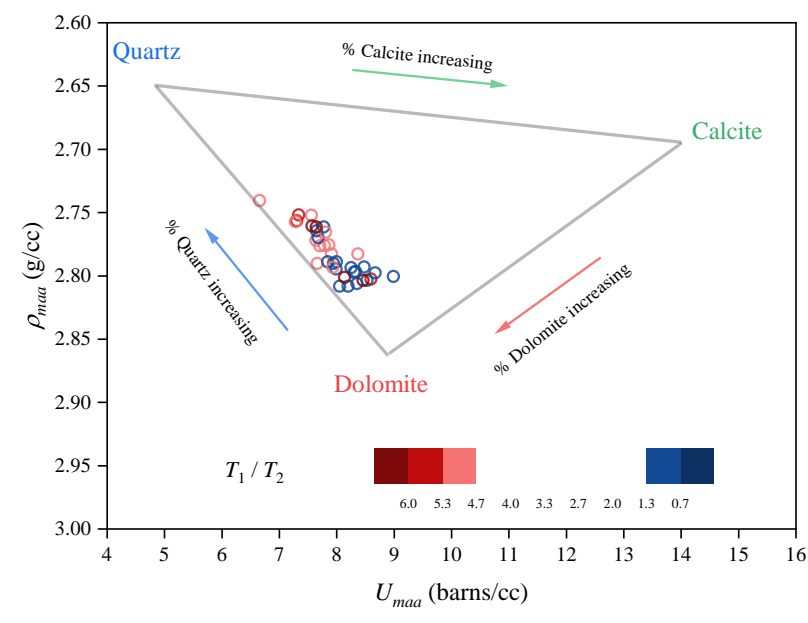

(b)

Fig. 5. a) $U_{\text {maa }}-\rho_{\text {maa }}$ crossplot (MID plot) with superimposed $T_{1} / T_{2}$, b) MID plot with only $T_{1} / T_{2}$ higher than 4.7 and lower than 1.3 . $T_{1} / T_{2}$ are presented by circles in color with a range from 0.66 to 7.44. Gray lines link mineral end members of a ternary mixture of quartz, calcite, and dolomite. Arrows indicate an increasing percentage of the end-member minerals. Note the extreme values of high and low $T_{1} / T_{2}$ appear in high dolomite end. 
Table 2. Average values of calculated log responses.

\begin{tabular}{lllllllll}
\hline $\begin{array}{l}\text { Sub-facies } \\
\text { (Based on core) }\end{array}$ & $\begin{array}{l}\text { NPHI } \\
(\%)\end{array}$ & $\begin{array}{l}\text { CT90 } \\
(. \mathrm{mmo} / \mathrm{m})\end{array}$ & $\begin{array}{l}\text { GRTO } \\
(. \mathrm{api})\end{array}$ & $\begin{array}{l}\text { POTA } \\
(. \mathrm{ppm})\end{array}$ & $\begin{array}{l}\text { THOR } \\
(. \mathrm{ppm})\end{array}$ & $\begin{array}{l}\rho_{\text {maa }} \\
(\mathrm{gm} / \mathrm{cc})\end{array}$ & $\begin{array}{l}U_{\text {maa }} \\
(\mathrm{barns} / \mathrm{cc})\end{array}$ & $T_{1} / T_{2}$ \\
\hline MS & 7.553 & 62.935 & 9.274 & 0.128 & 1.229 & 2.770 & 7.596 & 2.556 \\
PS & 7.847 & 63.429 & 9.659 & 0.144 & 1.096 & 2.774 & 7.786 & 2.502 \\
GS & 7.267 & 50.465 & 11.743 & 0.192 & 1.308 & 2.784 & 7.855 & 2.339 \\
IB & 6.272 & 76.566 & 9.238 & 0.150 & 1.381 & 2.764 & 7.492 & 1.834 \\
BC & 6.990 & 83.632 & 8.063 & 0.118 & 1.000 & 2.741 & 6.839 & 2.820 \\
\hline
\end{tabular}

Table 3. Correlations (or loadings), eigenvalues and variances of Principal Component 1 to 8 referenced to logs.

\begin{tabular}{lllllllll}
\hline & \multicolumn{7}{c}{ Principal Components } \\
\cline { 2 - 9 } & PC1 & PC2 & PC3 & PC4 & PC5 & PC6 & PC7 & PC8 \\
\hline NPHI & 0.070 & 0.846 & 0.352 & -0.087 & 0.337 & 0.169 & 0.033 & -0.057 \\
GRTO & -0.008 & -0.083 & -0.049 & 0.087 & 0.372 & 0.040 & 0.350 & 0.849 \\
CT90 & -0.295 & 0.111 & 0.271 & 0.869 & -0.195 & -0.174 & 0.064 & 0.002 \\
$\rho_{\text {maa }}$ & 0.570 & -0.157 & 0.122 & 0.277 & -0.160 & 0.721 & 0.106 & -0.039 \\
$U_{\text {maa }}$ & 0.754 & 0.008 & 0.082 & 0.135 & 0.098 & -0.621 & -0.107 & 0.029 \\
POTA & -0.011 & -0.188 & -0.080 & 0.085 & 0.464 & -0.077 & 0.683 & -0.513 \\
THOR & -0.042 & -0.088 & -0.341 & 0.321 & 0.624 & 0.168 & -0.586 & -0.102 \\
$T_{1} / T_{2}$ & -0.113 & -0.443 & 0.810 & -0.160 & 0.264 & 0.004 & -0.199 & -0.015 \\
\hline Eigenvalue & 2.893 & 0.732 & 0.509 & 0.294 & 0.219 & 0.124 & 0.084 & 0.006 \\
Variance & 0.595 & 0.151 & 0.105 & 0.060 & 0.045 & 0.026 & 0.017 & 0.001 \\
Cumulative variance & 0.595 & 0.746 & 0.850 & 0.911 & 0.956 & 0.982 & 0.999 & 1.000 \\
\hline
\end{tabular}

breccia. Meanwhile, similar to the observed trend of $T_{1} / T_{2}$, the GRTO, $\rho_{\text {maa }}$, and $U_{\text {maa }}$ data are showing either descending or ascending trends following the lithologic succession of mudstone, packstone, and grainstone.

The result from PCA provides eigenvalues, eigenvector loadings, and variance of each principal component referenced to eight logs (Table 3). The Pareto distribution of eight eigenvalues for each eigenvector (Fig. 6) illustrates that the first two principal components account for $74.6 \%$ of the total variability. Fig. 7 shows the biplot of PC1 and PC2, where

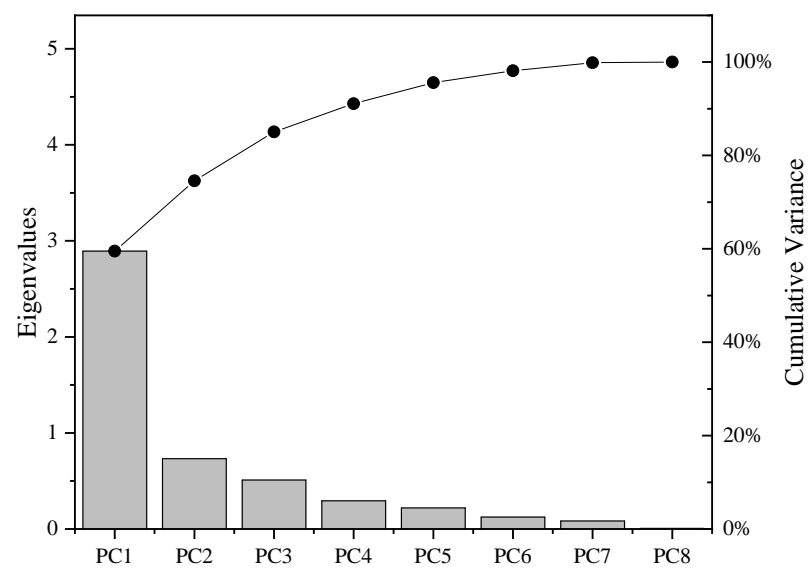

Fig. 6. Pareto plot for PCA. Bars represent eigenvalues and relative variances of the principal components. loading vectors show the contribution of original variables (logs) to PC1 and PC2 and the correlations among original variables. If two vectors are close and form a small angle, the two input logs are well correlated (Martinez and Kak, 2001;

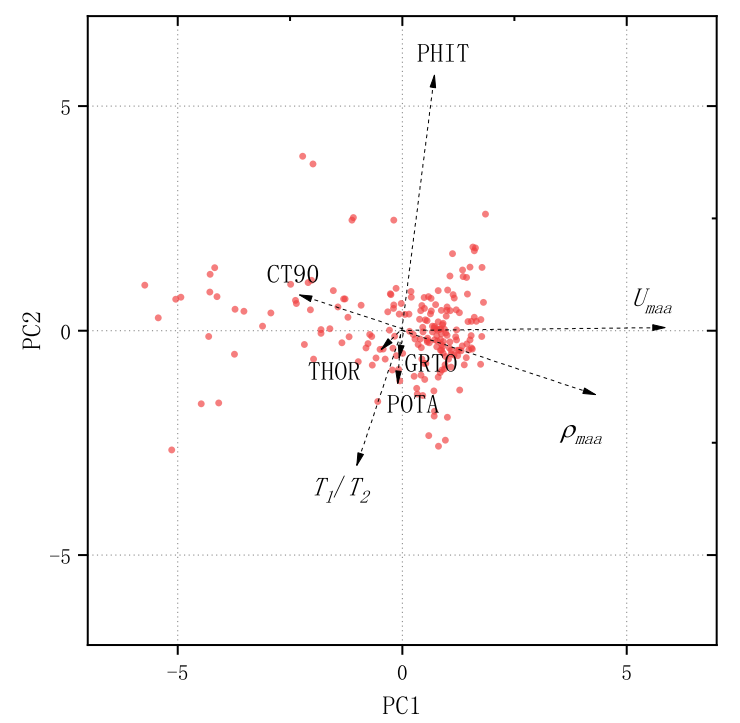

Fig. 7. Biplot of PC1 versus PC2 from PCA. Arrows represent eigenvectors of corresponding logs. The loadings determine the length and position of eigenvectors on PC1 and PC2. Note that a smaller angle between two loading vectors indicating the closer correlation between the input variables (logs) corresponding to loading vectors. 
Doveton, 2014). The length of vectors represents the variance of each principal component gained from original logs. Indicated in Table 3 and Fig. 7, THOR, POTA, and GRTO all have very low weights on the first two principal components. The $\rho_{\text {maa }}$ and $U_{\text {maa }}$ vectors point to high positive loadings toward PC1 and low positive loading toward PC2, which are negatively correlated with CT90. The PHIT and $T_{1} / T_{2}$ show high loadings towards PC2.

The PCA results provide some preliminary links between logs and lithologies. For instance, the low loadings of THOR, POTA, and GRTO reveal the minor impact of clay content on differentiating carbonate sub-facies in this case. Also, the fact that CT90, $\rho_{\text {maa }}$, and $U_{m a a}$ contribute to most variance on PC1 while PHIT and $T_{1} / T_{2}$ count more for PC2, gives the non-uniqueness correlation between porosity and permeability (Babadagli and Al-Salmi, 2004; Ehrenberg and Nadeau, 2005; Doveton, 2014).

\subsubsection{Cluster analysis results}

We need to determine the number of expected clusters as a priori information when defining clusters. In this study, since the clustering algorithm-FCM is an unsupervised method, an accurate number of clusters is required during the self-training process (Bezdek et al., 1984; Zadeh, 1996). The number of clusters is fixed as five, corresponding to five primary subfacies (mudstone, packstone, grainstone, incipient breccia, and breccia). Initially, five cluster centers are inserted randomly on the Euclidean space of the PC1-PC2 cross plot, and selftraining starts with an initial guess of cluster membership values $\mu_{i j}$. We then calculated and updated the objective function of all five clusters until the stopping criteria is met. At iteration 11, the objective function meets the minimum threshold, and the updated centers (crosses in color) are superimposed with clusters of principal component scores in Fig. 8. The PC1 reasonably maps EFs as EF1-3 plot in positive PC1 regime, whereas EF4-5 have negative PC1 values. EF4 tends to be more distinctive with lower PC1 values and can be easily differentiated from other EFs. Meanwhile, EF1, EF2, and EF3 are heavily overlapping, elucidating the importance of implementing a fuzzy membership clustering algorithm instead of hard-boundary algorithms.

\subsubsection{Classification results}

To achieve the unsupervised classification of electrofacies generated in the last step, we followed the following steps. First, five electrofacies are assigned with five sub-facies with no repetition, then $S$ in Eq. (10) is calculated. This step is repeated with different permutations of lithologies $k$ times, where $k$ is 120 for 5 clusters. Finally, the analysis picks the combination that minimizes $S$ as the lithologies matching electrofacies. As a result, EF1-5 clustered in Fig. 8 are assigned to mudstone, packstone, grainstone, incipient breccia, and breccia, respectively. The classification shows that EF1, $\mathrm{EF} 2$, and EF3 with positive PC1 scores suggest non-breccia carbonate (mudstone, packstone, grainstone), and EF4, EF5 with negative PC1 scores suggest breccia carbonate (incipient breccia and breccia).

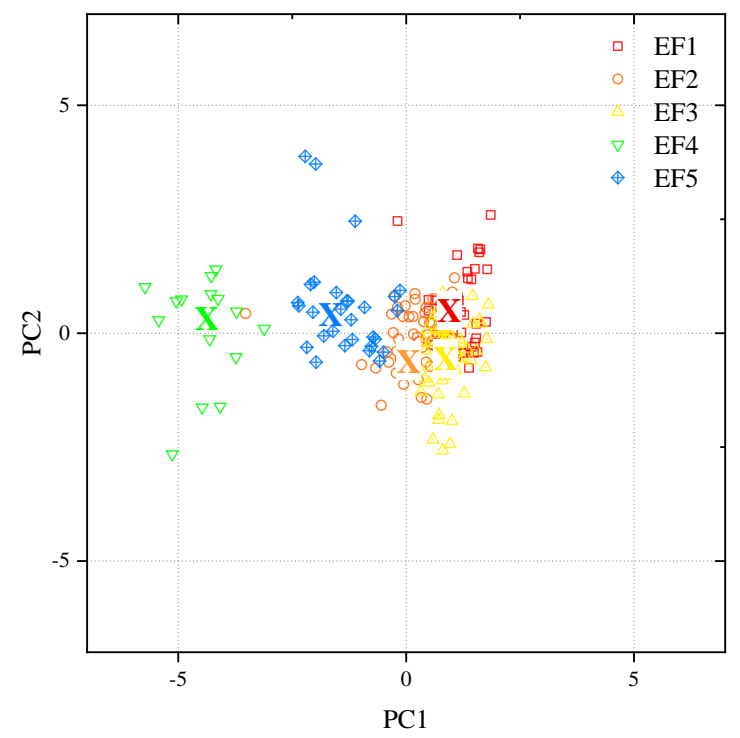

Fig. 8. Score plot of PC1 and PC2 with classified clusters and cluster centers as the results of cluster analysis. Five clusters are marked in different colors and symbols. The cluster centers are presented as ' $\mathrm{X}$ ' marks with the same color of belonging clusters. Interpreted electrofacies by the classification analysis are assigned to corresponding clusters. Note the clusters of EF1, EF2, and EF3 overlap considerably.

The clear separation of breccia and non-breccia validates the distinct average log values in Table 2. Three non-breccia carbonate clusters overlap and have very close cluster centroids, due to their similar textures and petrophysical responses. In contrast, incipient breccia and breccia can be distinguished very well, as PC1 and PC2 scores are more distinctive as a result of the dissimilarity of petrophysical responses (Table 2). The breccia samples in the Arbuckle Group were formed due to the collapse of paleokarst features, and they were locally cemented with micrite (Franseen, 2000; Franseen et al., 2003). Brecciation and fracturing fabricate vuggy porosity, whereas the autoclasts (typically from mudstones and wackestones) were better cemented. As a result, despite the low PHIT, breccia samples are more conductive due to the well-connected vuggy pores and intercrystalline pores.

\subsubsection{Predicted carbonate sub-facies}

To quantitatively assess if $T_{1} / T_{2}$ can improve the accuracy of prediction of carbonate sub-facies, a series of electrofacies discrimination was conducted with different variable sets. Most borehole-based carbonate reservoir characterizations utilize density, neutron, conductivity, and gamma-ray logs (Dorfman et al., 1990; Lee et al., 2002; Perez et al., 2005; Asgari and Sobhi, 2006). To set the control group, we use PHIT, total gamma-ray, and lateral $\log 90$ inches conductivity as the primary input variable set, namely Set 1 , for electrofacies classification. $T_{1} / T_{2}$ was then added to the primary input dataset to form the second input variable set Set 2. Set 3 contains the full suite of $\log$ except $T_{1} / T_{2}$, and it was tested as a third input variable set. Finally, the full log suite, including $T_{1} / T_{2}$ serves as the fourth input variable set (Set 4). Each variable set was used as an input for PCA, clustering analysis, and classification, generating four facies profiles. 


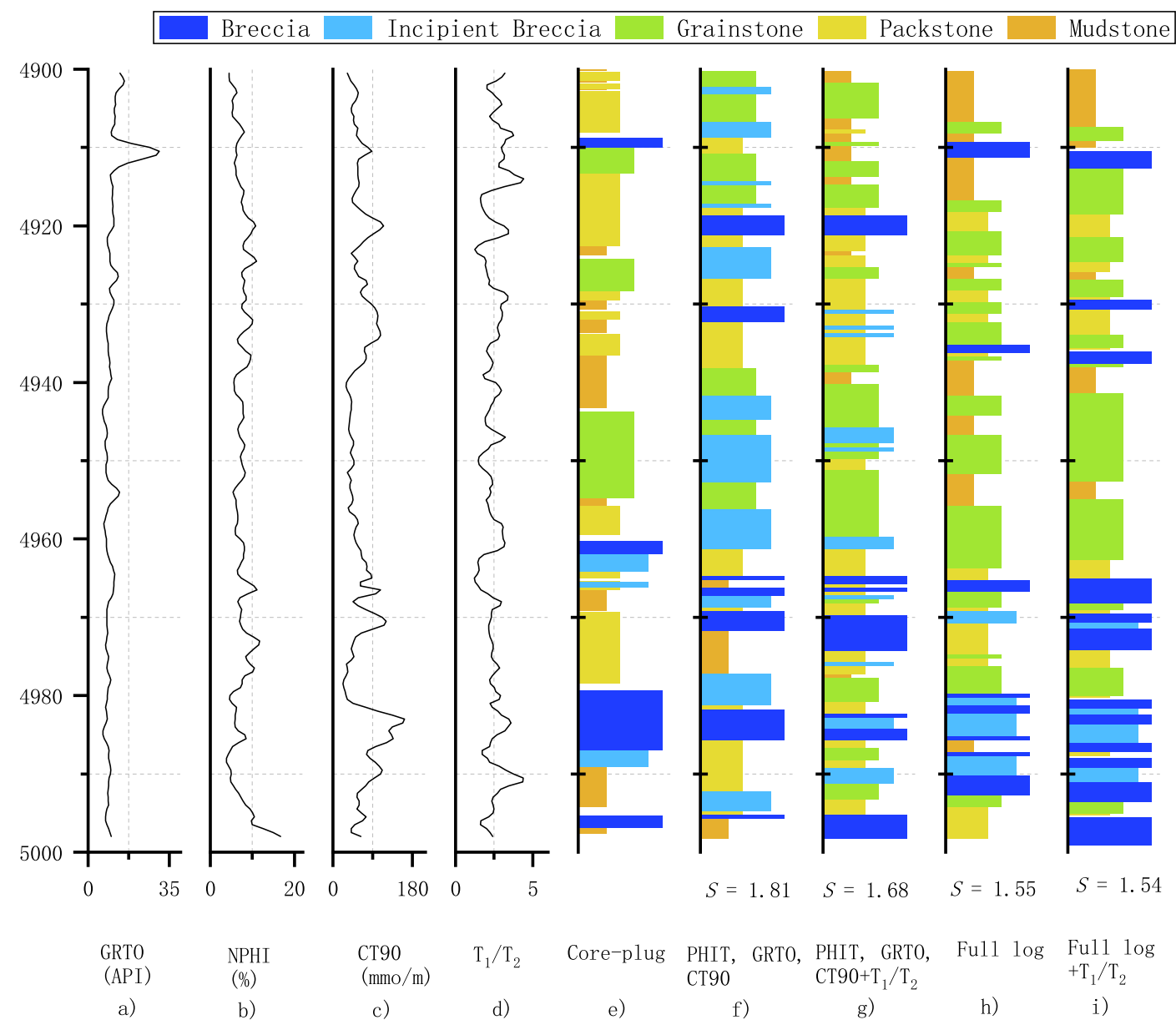

Fig. 9. Comparison of logs, lithologies, and eletrofacies predicted by four different datasets, plotted against depth. a)-c) GRTO, NPHI, and CT90 logs collected from well Wellington KGS \#1-32 (4900 - 5000 ft), d) $T_{1} / T_{2}$ curve, e) Carbonate sub-facies determined from core observation, f)-i) Electrofacies predicted with Dataset 1 including PHIT, GRTO, and CT90 with a recognition error $S=1.81$, dataset 2 (PHIT, GRTO, CT90, $T_{1} / T_{2}$ ) with $S=1.68$, dataset 3 (PHIT, GRTO, CT90, THOR, POTA, $\rho_{\text {maa }}, U_{\text {maa }}$ ) with $S=1.55$, and dataset 4 (PHIT, GRTO, CT90, THOR, POTA, $\rho_{\text {maa }}, U_{\text {maa }}, T_{1} / T_{2}$ ) with $S=1.54$.

Fig. 9 is the predicted facies from each variable set. For additional reference, GRTO, NPHI, CT90, $T_{1} / T_{2}$ curves (Fig. 9(a)-9(d)), and an actual sub-facies profile (Fig. 9(e)) from core-plug observations are also provided in Fig. 9. The core plug lithologies are identified from both full core description and special core analysis.

The value of objective function $S$ provides a means to compare the prediction accuracy of each variable set and a lower $S$ value indicates better accuracy on prediction lithologies. Set $1,2,3$, and 4 have $S=1.81,1.68,1.55$, and 1.54, respectively. The outcome of Set 1 (Fig. 9(f)) serves as a baseline of the prediction and it has the lowest accuracy, especially in differentiating breccias from other lithologies. Adding $T_{1} / T_{2}$ to Set 1 builds Set 2 (Fig. 9(g)) and its $S$ value decreases from 1.81 to 1.68 . Moreover, Set 2 lowers the misprediction rate of lithologies from 0.79 to 0.66 and also decreases the number of incorrect predictions between non-breccia carbonates and breccia carbonates. Therefore, the introduction of $T_{1} / T_{2}$ increased the prediction accuracy relative to the control group Set 1. The results from Set 3 (Fig. 9(h)) and Set 4 (Fig. 9(i)), which include more mineralogy related parameters (THOR, POTA, $\rho_{\text {maa }}, U_{\text {maa }}$ ), outperform Sets 1 and 2 with minimized objective function values. Both Set 3 and Set 4 successfully discern a breccia layer $(4910 \mathrm{ft})$ that is missed in Set 1 and 2 which is characterized by a relatively high GRTO value (Fig. 9(a)). However, comparing the $\mathrm{S}$ values of Set 4 and Set 3, the inclusion of $T_{1} / T_{2}$ in Set 4 does not improve the assessment of Set 3 remarkedly. The outcomes indicate that 1) $T_{1} / T_{2}$ does not significantly correlate with clay content; 2) $T_{1} / T_{2}$ provides information partly redundant with other mineralogy related well logs; 3 ) $T_{1} / T_{2}$ can improve carbonate sub-facies determination when the gamma-ray and photoelectric logs are missing. However, $T_{1} / T_{2}$ is not essentially a substitute for the gamma-ray and photoelectric logs.

\subsection{Limitation of NMR logging tools}

The sensitivity of apparent $T_{1} / T_{2}$ values to lithology is based on the correlation between $T_{1} / T_{2}$ and other lithology indicators such as porosity, conductivity, gamma-ray, and the $\rho_{\text {maa }}$ versus $U_{\text {maa }}$ plot. However, our sub-facies identification including in carbonate strata does not provide satisfactory results. Here we discuss the possible factors that affecting $\operatorname{logging} T_{1} / T_{2}$. 
The MRIL tool collects relaxation time distribution as a scattered 10 points spectra ranging from $2 \mathrm{~ms}$ to 2048 $\mathrm{ms}$. First, there is no recorded signals under $2 \mathrm{~ms}$, resulting the missing of major peaks for formations are dominated by small pores. Additionally, 10 points spectra is too sparse to recover the actural relaxation time distribution and peaks might have been merged. Due to both reasons, $T_{1} / T_{2}$ valued could be skewed from Eq. (7). Furthermore, considering MRIL's large peneatration area, it suffers from so-called 'bed boundary effect,' which describes the the merging of geophysical responses from distinct thin layers/beds in a single NMR measurement (Kleinberg et al., 1993b). This leads to the discrepancy of the resolution between $T_{1}$ and $T_{2}$ measurement, as well as discrepancies between MRIL and other logs. Since $T_{1}$ measurement requires an longer acquisition time than $T_{2}$ measurement, allowing more signal merging, therefor it affects the $T_{1} / T_{2}$ values. Lastly, as we are linking lithologies determined from small scale core plugs with moving average log data from a much larger inverstigation area, such crossscale projection might introduce errors to the prediction of lithologies due to the scaling issue. Future works can help eliminate such systimatic errors in $T_{1} / T_{2}$ by improving MRIL instrumentation to provide shorter deadtime and finer recording intervals.

\subsection{Impact of fluid type on $T_{1} / T_{2}$}

$T_{1}$ and $T_{2}$ are dependent not only on lithology but also on the reservoir fluid types. Since the NMR signal is directly sensitive to the hydrogen content in either water or hydrocarbon and the fluid's environment, $T_{1}$ and $T_{2}$ could capture the fluid properties and fluid-rock interactions. Viscosity, one of the most important fluid properties, turns to play a vital role in controlling the hydrogen motion and variations of $T_{1} / T_{2}$. Initially, the $T_{1} / T_{2}$ ratio was considered as a constant in brinesaturated rock samples under low-frequency magnetic field (2 MHz) (Kleinberg et al., 1993b; Freedman and Morriss, 1996). Later studies by (Straley, 1997; Coates et al., 1999) demonstrated $T_{1} / T_{2}$ is sensitive to fluid types in the presence of mixed fluids in oil shale and gas shale samples. Comparing to $T_{1} / T_{2}$ value of water which is $1-2$, highly viscous hydrocarbon fluids have higher $T_{1} / T_{2}$ value (up to 100), whereas light oils and gas with low viscosity have lower $T_{1} / T_{2}$ (4-20) (Coates et al., 1999; Freedman et al., 2001). The results conducted by Washburn and Birdwell (2013) and Fleury and RomeroSarmiento (2016) show that bitumen, heavy oil, and methane have high $T_{1} / T_{2}$ and their presence in the sample could increase the overall $T_{1} / T_{2}$.

Wellington \#1-32 is not a producing well, and the Arbuckle Group in this area is extensively water-flooded, left with bare residual oil. However, gas may still be a confounding factor driving $T_{1} / T_{2}$ values in Arbuckle. The dependency of fluid in deriving $T_{1} / T_{2}$ is also notable in the PCA results. According to the loadings of each component referenced to input variables (Table 3 ), the $T_{1} / T_{2}$ vector has relatively low loadings on both PC1 and PC2 compared with other logs, and the maximum correlation between $T_{1} / T_{2}$ and principal component appears in PC3 with a very high loading of 0.810 .
This indicates that the change in $T_{1} / T_{2}$ values heavily depends on the parameters that are not strongly associated with other input variables. However, $T_{1} / T_{2}$ is the only input variable sensitive to both fluid types and lithology, resulting in similar sub-facies classification for Set 3 and Set 4.

Even with such non-unique sensitivity, $T_{1} / T_{2}$ still has the potential to be an rock type indicator as long as the effects of fluids are well calibrated. Researchers have developed new insights into multi-phase flow in carbonate rocks under low magnetic field, for example, the application of 2-D $T_{1}-T_{2}$ map is an effective way to recognize multi fluid phases simultaneously and it has become a popular means for fluid typing (Fleury and Romero-Sarmiento, 2016; Mailhiot et al., 2017). Engaging such methods, we believe future studies can derive a modified $T_{1} / T_{2}$ value that is exclusively representative of the lithology.

\subsection{Other factors that may fail electrofacies recognition}

Lithologies sometimes cannot be tied to electrofacies (petrophysical facies) due to 1) the applied statistical analysis is not sensitive to the subtle changes of logs between facies (Brandsegg et al., 2010; Doveton, 2014); and/or 2) scaling and resolution issues arose from well $\log$ and laboratory measurements (Hurlimann et al., 2005).

In this case study, the targeting zone is restricted within 100 feet interval. The change of lithology is limited within this interval, thus leading to an insignificant change of log data for electrofacies recognition. The gamma-ray log shows a very typical response for clean sedimentary rocks. Except for 4955-4961 ft., where gamma-ray values reach 45 API units, the section has the uniformly low readings (Fig. 9(a)), indicating clean carbonate with low clay content. Similarly, the trace of deep resistivity (RDEP) changes only slightly, within one order of magnitude, suggesting relatively homogenous pore attributes and mineral composition at the resolution scale of the $\log$. This interpretation is consistent with the readings in $U_{\text {maa }}-\rho_{\text {maa }}$ MID plot (Fig. 5). Therefore, although eight different logs are applied to the electrofacies recognition, they may not provide enough variation that the statistical methods need to differentiate sub-facies of carbonate.

The application of conventional multivariate statistical methods (e.g., PCA, cluster analysis, and discriminant analysis using well logs) have succeeded in predicting electrofacies and permeability in many carbonate reservoirs (Burke et al., 1969; Chang et al., 1997; Qi and Carr, 2006; Doveton, 2014). Those studies documented that, without core calibration, the accuracy of recognizing sub-facies of carbonate is low, compared to the accuracy of distinguishing between sandstone and shale. Our study is consistent with the results from Dorfman et al. (1990), Lee et al. (2002), and Criollo et al. (2016), and El Sharawy and Nabawy, (2016). El Sharawy and Nabawy (2016) documented their statistical methods failed to discern the difference between dolomitic limestone and limestone, although they did successfully recognize sandstone, shale, and limestone. Brandsegg et al. (2010) and Doveton (2014) suggest that since PCA is a linear dimentionality reduction 
method, the distance between and within lithologies are considered with the same scale. As a result, variability of subfacies in a fairly uniform lithologies will be masked by the varibility between major lithologies. To solve that problem, one should consider either a structured PCA which analyzes sub-facies independently (Brandsegg et al., 2010) or a nonlinear dimensionality reduction method (e.g., T-distributed Stochastic Neighbor Embedding (t-SNE) method (Van Der Maaten, 2009)) to identify the variablity within one lithologies at different scales.

To improve the accuracy of electrofacies recognition and need to be constrained by more a priori information like depth. Furthermore, the infucluence from fluid should be eliminated by using $T_{1}-T_{2}$ map and also permeability should be calculated to compare with core-permeability which provides a more practical evaluation of the reservoir quality.

\section{Conclusion}

To fully exploit the potential application of the NMR $\log$ in reservoir characterization, this study investigates the feasibility of $T_{1} / T_{2}$ in lithologies recognition within a dolostone reservoir. Logging data and core plugs from of a total $100 \mathrm{ft}$ interval were analyzed and measured. We established the sensitivity of $T_{1} / T_{2}$ to lithology by comparing $T_{1}, T_{2}$, and $T_{1} / T_{2}$ characteristics from both log and lab NMR measurements. To validate the inferences of $T_{1} / T_{2}$, electrofacies were analyzed and defined through PCA, clustering, and classification. The results show that among five electrofacies, incipient breccia and breccia are more distinct while mudstone, packstone and grainstone are heavily overlapping. The comparison of classification results between Set 1 (PHIT, GRTO, and CT90), and Set 2 (Set 1 with $T_{1} / T_{2}$ ) indicates that addition of $T_{1} / T_{2}$ reduced the recognition error from 1.81 to 1.68 (unitless) whereas the errors of Set 3 (Set 1 with THOR, POTA, $\rho_{\text {maa }}, U_{\text {maa }}$ ) and Set 4 (Set 3 with $\left.T_{1} / T_{2}\right)$ are close (1.55 and 1.54$)$. These outcomes suggest that adding $T_{1} / T_{2}$ can improve the classification accuracy, especially for incipient breccia, when THOR, POTA, $\rho_{\text {maa }}$, $U_{\text {maa }}$ data are not available. However, $T_{1} / T_{2}$ failed to improve the classification accuracy when the entire suite of logs are available. Collectively, our results show: 1) $T_{1} / T_{2}$ is a lithology indicator but cannot substitute other logs like gamma-ray and photoelectric $\log$ in carbonate sub-facies determination; 2) instrumental limitation of MRIL and lacking of 2-D $T_{1}-T_{2}$ map make $T_{1} / T_{2}$ ratio from log less representative; 3 ) variance of $T_{1} / T_{2}$ inside one sample should be considered as another lithology indicator.

This study exploits the potential of borehole NMR data, which focuses on investigating the inferences from NMR longitudinal and transverse relaxation time ratio on electrofacies classification and lithologies identification. The analysis suggests beyond traditionally considered parameters, NMR $\log$ can characterize the petrophysical properties of reservoirs. Nonetheless, challenges remain in the interpretation of data, such as how to connect the physical meanings of relaxivity change to mineralogy change, and how to eliminate the impact of hydrocarbon to get a more representative $T_{1} / T_{2}$ for certain lithology. Our study provided valuable evidence and credible elucidation of the importance and physicochemical mechanism of $T_{1} / T_{2}$, which is essential for deciphering NMR $\log$ in carbonate reservoirs.

\section{Acknowledgement}

This is an extended project of individual study with Dr. John Doveton (Kansas Geological Survey). We thank Dr. John Doveton for providing log data and essential instruction on data processing. We thank Dr. Lynn Watney (Kansas Geological Survey) for providing core samples from well Wellington \#1-32. The authors are grateful to the two anonymous reviewers for their detailed reviews and constructive comments which helped to improve this manuscript.

\section{Conflict of interest}

The authors declare no competing interest.

Open Access This article is distributed under the terms and conditions of the Creative Commons Attribution (CC BY-NC-ND) license, which permits unrestricted use, distribution, and reproduction in any medium, provided the original work is properly cited.

\section{References}

Ali, L., Bordoloi, S., Wardinsky, S. Modeling permeability in tight gas sands using intelligent and innovative data mining techniques. Paper SPE 116583 Presented at SPE Annual Technical Conference and Exhibition, Denver, Colorado, 21-24 September, 2008.

Asgari, A. A., Sobhi, G. A. A fully integrated approach for the development of rock type characterization, in a middle east giant carbonate reservoir. Journal of Geophysics and Engineering, 2006, 3(3): 260-270.

Babadagli, T., Al-Salmi, S. A review of permeabilityprediction methods for carbonate reservoirs using well$\log$ data. SPE Reservoir Evaluation \& Engineering, 2004, 7(2): 75-88.

Barwick, J. S. The Salina Basin of North-Central Kansas. AAPG Bulletin, 1928, 12(2): 177-199.

Bezdek, J. C. Pattern Recognition with Fuzzy Objective Function Algorithms. Berlin, Germany, Springer Science \& Business Media, 1981.

Bezdek, J. C., Ehrlich, R., Full, W. FCM: The fuzzy c-means clustering algorithm. Computers \& Geosciences, 1984, 10(2-3): 191-203.

Brandsegg, K. B., Hammer, E., Sinding-Larsen, R. A comparison of unstructured and structured principal component analyses and their interpretation. Natural Resources Research, 2010, 19(1): 45-62.

Bucheb, J. A., Evans, H. B. Some applications of methods used in electrofacies identification. The Log Analyst, 1994, 35(1).

Burke, J. A., Campbell, R. L., Schmidt, A. W. The lithoporosity cross plot a method of determining rock characteristics for computation of log data. Paper SPE 2771 Presented at SPE 1llinois Basin Regional Meeting, Evansville, Indiana, 30-31 October, 1969.

Busch, J. M., Fortney, W. G., Berry, L. N. Determination of lithology from well $\operatorname{logs}$ by statistical analysis. SPE Formation Evaluation, 1987, 2(4): 412-418. 
Callaghan, P. T. Principles of Nuclear Magnetic Resonance Microscopy. New York, USA, Oxford University Press, 1991.

Carr, H. Y., Purcell, E. M. Effects of diffusion on free precession in nuclear magnetic resonance experiments. Physical Review, 1954, 94(3): 630-638.

Chang, H. C., Chen, H. C., Fang, J. H. Lithology determination from well logs with fuzzy associative memory neural network. IEEE Transactions on Geoscience and Remote Sensing, 1997, 35(3): 773-780.

Cheng, Y., Chen, S., Eid, M., et al. Determination of permeability from NMR $T_{1} / T_{2}$ ratio in carbonates. Paper SPWLA 2017 Presented at SPWLA 58th Annual Logging Symposium, Oklahoma, USA, 17-21 June, 2017.

Clavier, C., Rust, D. H. Mid plot: A new lithology technique. The Log Analyst, 1976, 17(6): 1-9.

Coates, G. R., Xiao, L., Prammer, M. G. NMR Logging: Principles and Applications. Houston, USA, Haliburton Energy Services Publication H02308, 1999.

Cole, V. B. Subsurface Ordovician-Cambrian Rocks in Kansas. Kansas Geological Survey, Kansas, USA, 1975.

Coman, R., Tietjen, H., Thern, H., et al. Improved NMR logging approach to simultaneously determine porosity, $T_{2}$ and $T_{1}$. Paper SPE 175050 Presented at SPE Annual Technical Conference and Exhibition, Houston, Texas, 28-30 September, 2015.

Criollo, D., Marin, Z., Vasquez, D. Advanced electrofacies modelling and permeability prediction: A case study incorporating multi-resolution core, NMR and image log textural information into a carbonate facies study. Paper SPE 175050 Presented at 22 $2^{\text {nd }}$ Formation Evaluation Symposium of Japan, Chiba, Japan, 29-30 September, 2016.

Delfiner, P. C., Peyret, O., Serra, O. Automatic determination of lithology from well logs. SPE Formation Evaluation, 1987, 2(3): 303-310.

d'Eurydice, M. N., Montrazi, E. T., Fortulan, C. A., et al. $T_{2}-$ filtered $T_{2}-T_{2}$ exchange NMR. The Journal of Chemical Physics, 2016, 144(20): 204201.

Dewan, J. T. Essentials of Modern Open-Hole Log Interpretation. Tulsa, USA, PennWell, 1983.

Dorfman, M. H., Newey, J. J., Coates, G. New techniques in lithofacies determination and permeability prediction in carbonates using well logs. Geological Society, London, Special Publications, 1990, 48(1): 113-120.

Doveton, J. H. Principles of Mathematical Petrophysics. Oxford, UK, Oxford University Press (UK), 2014.

Doveton, J. H., Cable, H. W. Fast matrix methods for the lithological interpretation of geophysical logs. Geomathematical and Petrophysical Studies in Sedimentology, 1979, 1979: 101-116.

Doveton, J. H., Watney, L. Textural and pore size analysis of carbonates from integrated core and nuclear magnetic resonance logging: An arbuckle study. Interpretation, 2015, 3(1): SA77-SA89.

Dunn, J. C. A fuzzy relative of the isodata process and its use in detecting compact well-separated clusters. Journal of Cybernetics, 1973, 3(3): 32-57.
Dunn, K. J., Bergman, D. J., LaTorraca, G. A. Nuclear Magnetic Resonance: Petrophysical and Logging Applications. Amsterdam, the Netherlands, Elsevier, 2002.

Ehrenberg, S. N., Nadeau, P. H. Sandstone vs. Carbonate petroleum reservoirs: A global perspective on porositydepth and porosity-permeability relationships. AAPG Bulletin, 2005, 89(4): 435-445.

El Sharawy, M. S., Nabawy, B. S. Determination of electrofacies using wireline logs based on multivariate statistical analysis for the kareem formation, gulf of suez, egypt. Environmental Earth Sciences, 2016, 75(21): 1394.

Flaum, C., Pirie, G. Determination of lithology from induced gamma-ray spectroscopy. Paper SPWLA 1981 Presented at the SPWLA $22^{\text {nd }}$ Annual Logging Symposium, Mexico City, Mexico, 23-26 June, 1981.

Fleury, M., Romero-Sarmiento, M. Characterization of shales using $T_{1}-T_{2}$ NMR maps. Journal of Petroleum Science and Engineering, 2016, 137: 55-62.

Franseen, E. K. A review of arbuckle group strata in kansas from a sedimentologic perspective: Insights for future research from past and recent studies. The Compass: Earth Science Journal of Sigma Gamma Epsilon, 2000, 75(2-3): 68-89.

Franseen, E. K., Byrnes, A. P., Cansler, J. R., et al. Geologic controls on variable character of Arbuckle reservoirs in Kansas: An emerging picture. Kansas Geological Survey, Open-file Report, 2003, 59: 1-30.

Freedman, R., Lo, S., Flaum, M., et al. A new NMR method of fluid characterization in reservoir rocks: Experimental confirmation and simulation results. SPE Journal, 2001, 6(4): 452-464.

Freedman, R., Morriss, C. E. Apparatus including multi-wait time pulsed nmr logging method for determining accurate $T_{2}$-distributions and accurate $T_{1} / T_{2}$ ratios and generating a more accurate output record using the updated $T_{2}$ distributions and $T_{1} / T_{2}$ ratios. USA, US5486762A, 1996.

Godefroy, S., Korb, J. P., Fleury, M., et al. Surface nuclear magnetic relaxation and dynamics of water and oil in macroporous media. Physical Review E, 2001, 64(2): 021605 .

Grimm, E. C. Coniss: A fortran 77 program for stratigraphically constrained cluster analysis by the method of incremental sum of squares. Computers \& Geosciences 1987, 13(1): 13-35.

Hurlimann, M. D., Flaum, C., Flaum, M., et al. Nuclear magnetic resonance method and logging apparatus for fluid analysis. USA, US6891369B2, 2005.

Jain, A. K. Data clustering: 50 years beyond k-means. Pattern Recognition Letters, 2010, 31(8): 651-666.

Jolliffe, I. Principal Component Analysis. Berlin, Germany, Springer, 2011.

Kenyon, W. E., Day, P. I., Straley, C., et al. A three-part study of NMR longitudinal relaxation properties of watersaturated sandstones. SPE Formation Evaluation, 1988, 3(3): 622-636.

Khetrapal, C. L., Kunwar, A., Tracey, A., et al. NMR Basic Principles and Progress. Berlin, Germany, Springer, 1975. 
Kim, H. M., Mallick, B. K., Holmes, C. C. Analyzing nonstationary spatial data using piecewise gaussian processes. Journal of the American Statistical Association, 2005, 100(470): 653-668.

Kleinberg, R. L., Farooqui, S. A., Horsfield, M. A. $T_{1} / T_{2}$ ratio and frequency dependence of NMR relaxation in porous sedimentary rocks. Journal of Colloid and Interface Science, 1993a, 158(1): 195-198.

Kleinberg, R. L., Kenyon, W. E., Mitra, P. P. Mechanism of NMR relaxation of fluids in rock. Journal of Magnetic Resonance, Series A, 1994, 108(2): 206-214.

Kleinberg, R. L., Straley, C., Kenyon, W. E., et al. Nuclear magnetic resonance of rocks: $T_{1}$ vs. $T_{2}$. Paper SPE 26470 Presented at SPE Annual Technical Conference and Exhibition, Houston, Texas, 3-6 October, 1993b.

Korb, J. P., Whaley-Hodges, M., Bryant, R. G. Translational diffusion of liquids at surfaces of microporous materials: Theoretical analysis of field-cycling magnetic relaxation measurements. Physical Review E, 1997, 56(2): 19341945.

Lee, S. H., Kharghoria, A., Datta-Gupta, A. Electrofacies characterization and permeability predictions in complex reservoirs. SPE Reservoir Evaluation \& Engineering, 2002, 5(3): 237-248.

Lim, J. S., Park, H. J., Kim, J. A new neural network approach to reservoir permeability estimation from well logs. Paper SPE 100989 Presented at SPE Asia Pacific Oil \& Gas Conference and Exhibition, Adelaide, Australia, 11-13 September, 2006.

Lucia, F. J. Carbonate reservoir characterization: An integrated approach. Berlin, Germany, Springer, 2007.

Mailhiot, S. E., Williamson, N. H., Brown, J. R., et al. $T_{1}-T_{2}$ correlation and biopolymer diffusion within human osteoarthritic cartilage measured with nuclear magnetic resonance. Applied Magnetic Resonance, 2017, 48(4): 407-422.

Martinez, A. M., Kak, A. C. Pca versus lda. IEEE Transactions on Pattern Analysis and Machine Intelligence, 2001, 23(2): 228-233.

Mathisen, T., Lee, S. H., Datta-Gupta, A. Improved permeability estimates in carbonate reservoirs using electrofacies characterization: A case study of the north robertson unit, west texas. Paper SPE 70034 Presented at SPE Permian Basin Oil and Gas Recovery Conference, Midland, Texas, 15-17 May, 2001.

McDonald, P. J., Korb, J. P., Mitchell, J., et al. Surface relaxation and chemical exchange in hydrating cement pastes: A two-dimensional NMR relaxation study. Physical Review E, 2005, 72(1): 011409.

Meiboom, S., Gill, D. Modified spin-echo method for measuring nuclear relaxation times. Review of Scientific Instruments, 1958, 29(8): 688-691.

Perez, H. H., Datta-Gupta, A., Mishra, S. The role of electrofacies, lithofacies, and hydraulic flow units in permeability predictions from well logs: A comparative analysis using classification trees. SPE Reservoir Evaluation \& Engineering, 2005, 8(2): 143-155.
Poupon, A., Hoyle, W. R., Schmidt, A. W. Log analysis in formations with complex lithologies. Journal of Petroleum Technology, 1971, 23(8): 995-1005.

Qi, L., Carr, T. R. Neural network prediction of carbonate lithofacies from well logs, big bow and sand arroyo creek fields, southwest kansas. Computers \& Geosciences, 2006, 32(7): 947-964.

Rastegarnia, M., Talebpour, M., Sanati, A. Prediction of electrofacies based on flow units using NMR data and svm method: A case study in cheshmeh khush field, southern iran. Journal of Petroleum Science and Technology, 2017, 7(3): 84-99.

Rokach, L., Maimon, O. Clustering Methods, in Data Mining and Knowledge Discovery Handbook. Boston, USA, Springer, 2005.

Roslin, A., Esterle, J. S. Electrofacies analysis for coal lithotype profiling based on high-resolution wireline log data. Computers \& Geosciences, 2016, 91: 1-10.

Serra, O. T., Abbott, H. The contribution of logging data to sedimentology and stratigraphy. Society of Petroleum Engineers Journal, 1982, 22(1): 117-131.

Sharma, P., Mamgain, G., Bahuguna, V., et al. Improved permeability estimates in carbonate reservoirs using electrofacies characterization: A case study of mumbai high south. Paper Presented at The $2^{\text {nd }}$ South Asain Geoscience Conference and Exhibition, New Delhi, India, 12-14 January, 2011.

Simpson, J. H., Carr, H. Y. Diffusion and nuclear spin relaxation in water. Physical Review, 1958, 111(5): 1201.

Skalinski, M., Gottlib-Zeh, S., Moss, B. Defining and predicting rock types in carbonates-preliminary results from an integrated approach using core and $\log$ data from the tengiz field. Petrophysics, 2006, 47(1): 328-340.

Song, Y. Q., Venkataramanan, L., Hürlimann, M. D., et al. $T_{1}-T_{2}$ correlation spectra obtained using a fast twodimensional laplace inversion. Journal of Magnetic Resonance, 2002, 154(2): 261-268.

Straley, C. An experimental investigation of methane in rock materials. Paper SPWLA 1997 Presented at SPWLA 38th Annual Logging Symposium, Houston, Texas, 1518 June, 1997.

Van Der Maaten, L. Learning a parametric embedding by preserving local structure. Artificial Intelligence and Statistics, 2009, 5: 384-391.

Washburn, K. E., Birdwell, J. E. Updated methodology for nuclear magnetic resonance characterization of shales. Journal of Magnetic Resonance, 2013, 233: 17-28.

Westphal, H., Surholt, I., Kiesl, C., et al. Nmr measurements in carbonate rocks: Problems and an approach to a solution. Pure and Applied Geophysics, 2005, 162(3): 549-570.

Zadeh, L. A., Klir, G. J., Yuan, B. Fuzzy sets, fuzzy logic, and fuzzy systems: Selected papers. Singapore, World Scientific, 1996.

Zeller, D. E. Stratigraphic Succession in Kansas. Kansas Geological Survey Bulletin 189, 1968. 


\section{Appendix}

\section{Appendix A: Fuzzy-C mean algorithm}

A fuzzy c-mean process tries to minimize the primary objective function:

$$
J_{m}=\sum_{i=1}^{N} \sum_{j=1}^{C} \mu_{i j}^{m}\left\|x_{i}-c_{j}\right\|^{2}
$$

where $m$ is a real number $\in[1, \infty]$ called fuzziness index or factor, $\mu_{i j}$ is the degree of membership of $x_{i}$ in the cluster $j, x_{i}$ is the $i$ th of measured data in Euclidean space, $c_{j}$ is the center of the cluster in Euclidean space, and $\|*\|$ is the Euclidean distance between data $x_{i}$ and the cluster center $c_{j}$. Fuzzy partitioning is calculated by updating of fuzzy membership $\mu_{i j}$.

$$
\mu_{i j}=\frac{1}{\sum_{j=1}^{C}\left(\frac{\left|x_{i}-c_{i}\right|}{\left|x_{i}-c_{j}\right|}\right)^{\frac{2}{m-1}}}
$$

moreover, the cluster centers $c_{i}$ by:

$$
c_{i j}=\frac{\sum_{i=1}^{C} x_{j} \mu_{i j}^{m}}{\sum_{i=1}^{C} \mu_{i j}^{m}}
$$

Repeating above steps through an iterative operation until the minimum objective function $J_{m}$ has been achieved or the termination criterion has been reached.

This study considers two-dimensional FCM analysis of PC1 and PC2, as derived from the log data. If only two possible electrofacies (A and B) have been assigned, a membership partitioning matrix for both k-means and FCM algorithm as $M_{K M}$ and $M_{F C M}$ includes:

$$
M_{K M}=\left[\begin{array}{cc}
0 & 1 \\
0 & 1 \\
1 & 0 \\
\vdots & \vdots \\
0 & 1
\end{array}\right], \quad M_{F C M}=\left[\begin{array}{cc}
0.3 & 0.7 \\
0.4 & 0.6 \\
0.8 & 0.2 \\
\vdots & \vdots \\
0.1 & 0.9
\end{array}\right]
$$

Numbers indicate the degree of membership that belongs to each electrofacies. For sample 1 in the first row, a data point belongs exclusively to electorfacies B with a degree of membership equal to 1 in the k-means algorithm, whereas in the FCM algorithm it belongs to electrofacies A with a membership coefficient of 0.3 and belongs to electrofacies B with a membership coefficient of 0.7. As an outcome, every data point will have a membership partitioning for each cluster and that membership represents the possibility of belonging to a cluster.

\section{Appendix B: Introduction to logs}

The most informative lithology log is spectral gamma-ray (SGR), which is based on the gamma-ray response to identify clay minerals from radioactivity emitted by isotopes of POTA, thorium, and uranium (K, Th, and U, respectively) series. Since uranium sometimes is high in minerals other than clays (for example, in dolomite), calibrated gamma-ray reading (CGR) which only includes POTA and thorium is used more commonly in determining clay content. Units with high CGR suggest shaly lithologies and low permeability zones, whereas low CGR commonly indicates clean sandstone or carbonate. The GR log usually is analyzed together with additional logs like density log, neutron log, or sonic slowness.

Like the GR log, both density and neutron logs are nuclear tools responding to gamma-ray scattering and neutron scattering effects caused by the formation matrix and pore-filling fluids. Porosity, bulk density and hydrogen content are the common outcomes of density and neutron logs. As a supplementary measurement of density log, photoelectric factor (PeF) provides a means to discriminate lithologies by analyzing the low-energy PE absorption which is mostly independent of porosity. The sonic log is based on propagation of acoustic waves through the section. It not only is used for porosity estimation and cement volumetric evaluation, but is also combined with density to produce impedance logs and synthetic seismic profiles which can be used to correct depth and seismic travel times.

Resistivity is another petrophysical property that indirectly reflects the permeability and fluid saturation of reservoirs which is challenging to measure. To solve the challenge of accurate measurement, numerous resistivity and induction logs have been introduced in modern wireline logging probes, including microlog (ML), medium and deep resistivity (MRT/DRT), conductivity 
(90 inches conductivity (CT90) is used in this thesis) and spontaneous potential (SP). These logs measure the resistivity of mudcake, flushed zone, uninvaded zone and formation fluid, respectively.

Additionally, recently developed electromagnetic logging tools provide additional information about pore structure and fluid type in the surrounding reservoir environment. Among those tools, magnetic resonance imaging logging (MRIL) has created excitement in the well logging community. Based on the same physical principle as its laboratory-scale counterpart, MRIL is used to reveal total fluid-filled porosity, pore-size distribution, fluid types, and fluid contents that can be used subsequently to determine permeability. Since the 1970s, significant advances have been made in NMR wireline tools. The new acquisition schemes and processing methods significantly improved data acquisition, data quality, and interpretation. 